\title{
Validation of Two Federal Health Insurance Survey Modules After Affordable Care Act Implementation
}

\author{
Joanne Pascale ${ }^{1}$, Angela Fertig ${ }^{2}$, and Kathleen Call ${ }^{3}$
}

\begin{abstract}
This study randomized a sample of households covered by one large health plan to two different surveys on health insurance coverage and matched person-level survey reports to enrollment records. The goal was to compare accuracy of coverage type and uninsured estimates produced by the health insurance modules from two major federal surveys - the redesigned Current Population Survey Annual Social and Economic Supplement (CPS) and the American Community Survey (ACS) - after implementation of the Affordable Care Act. The sample was stratified by coverage type, including two types of public coverage (Medicaid and a state-sponsored program) and three types of private coverage (employer-sponsored, non-group, and marketplace plans). Consistent with previous studies, accurate reporting of private coverage is higher than public coverage. Generally, misreporting the wrong type of coverage is more likely than incorrectly reporting no coverage; the CPS module overestimated the uninsured by 1.9 and the ACS module by 3.5 percentage points. Other differences in accuracy metrics between the CPS and ACS are relatively small, suggesting that reporting accuracy should not be a factor in decisions about which source of survey data to use. Results consistently indicate that the Medicaid undercount has been substantially reduced with the redesigned CPS.
\end{abstract}

Key words: Health insurance; validation; Affordable Care Act; marketplace.

\section{Introduction}

Surveys are the only source of data on the uninsured rate in the United States. The Affordable Care Act (ACA) introduced a certain amount of federal monitoring of insurance status through standardized Internal Revenue Service (IRS) forms (the 1095), but the potential for estimating insurance status from IRS data is in the early stages of exploration (Lurie and Pearce 2018). Thus, surveys remain the only source, and they are not without measurement error. For example, studies from the 1990s found the US uninsured rate ranged from a low of about $8 \%$ up to a high of almost $18 \%$ depending on the source (Bennefield 1996; Lewis et al. 1998; Rosenbach and Lewis 1998). Surveys generally derive the estimate of the uninsured by asking about coverage through a range of different sources or types of coverage, and then designating those with no reported coverage as uninsured. Therefore, to assess the accuracy of the uninsured estimate, misreporting of a broad range of plan types needs to be considered collectively. Put

${ }^{1}$ U.S. Census Bureau, 4600 Silver Hill Road, Suitland, MD 20233. U.S.A. Email: joanne.pascale@ census.gov

2 University of Minnesota, Humphrey School of Public Affairs, 130 Humphrey School, 301 19th Ave S, Minneapolis, 55455, U.S.A. Email: arfertig@umn.edu

3 State Health Access Data Assistance Center, 2221 University Ave SE \#345, Minneapolis, MN 55414. U.S.A.

Email: callx001@umn.edu 
another way, “. . .the uninsured are a residual group by definition. They are the people who fall in the cracks left by public and private insurance programs. . . As a result, one cannot produce or make sense of statistics about the uninsured without first producing or making sense of statistics about the insured." (Farley-Short 2001, 4)

Challenges in measuring health insurance in surveys have been well-documented since the 1980s (Blewett and Davern 2006; Lewis et al. 1998; Pascale 2008; Swartz 1986). For example, Medicaid is a major public insurance program for low-income families, and numerous studies have documented consistent and persistent under-reporting across a range of surveys (Blumberg and Cynamon 1999; Call et al. 2013; Czajka and Lewis 1999; Eberly et al. 2009; Klerman et al. 2009; Pascale et al. 2009; Rosenbach and Lewis 1998). Employer-sponsored insurance (ESI) dominates private coverage, and those without access to coverage through an employer, group or association often opt to purchase coverage directly from the insurer, which is known as non-group coverage. There is some evidence that reporting of private coverage is fairly accurate overall (Hill 2007; Nelson et al. 2000). However, other evidence suggests that non-group coverage is over-reported (Cantor et al. 2007), and that non-comprehensive non-group coverage (e.g., dental and vision plans) is often reported in tandem with another comprehensive plan, most often ESI coverage (Mach and O'Hara 2011).

In spite of the extensive research on public coverage, Medicaid has been studied in relative isolation from other plan types, and it is not entirely clear how misreporting of Medicaid affects estimates of other plan types, or whether over-reporting of Medicaid among those who are not enrolled may offset some Medicaid under-reporting. Studies that explore reporting accuracy of both public and private coverage, and how misreporting of one affects the other, are extremely rare. We know of only two (Davern et al. 2008; Nelson et al. 2000), and results are provocative. For example, ESI is by far the most prevalent source of coverage in the United States, so if even a small percentage of ESI enrollment is misreported as, say, public, this artificially inflates the public coverage estimate and offsets, to a large extent, the under-reporting of Medicaid, as was demonstrated by Davern et al. (2008). While results from these studies are highly valuable, both precede implementation of the ACA and neither examined the question series employed in major federal government surveys.

Indeed, the ACA added considerable complexity to the already complicated task of accurately categorizing health insurance coverage from surveys (Pascale 2016). One factor was the introduction of the "marketplace." This term has come to have a dual meaning. It is both a portal (aka: healthcare.gov) through which people can shop for and enroll in a range of coverage options - both public and private - and the term is commonly used to describe the coverage itself: non-group/direct-purchase coverage for which many enrollees receive a subsidy for the monthly premium. The ACA also further blurred the line between public and private coverage. Public and private coverage are often distinguished from each other by the party responsible for paying the monthly premium; if individuals and/or employers pay, the coverage is considered private, and if a government entity pays, it is considered public. However, even before the ACA, many states offered public programs (e.g., Children's Health Insurance Program (CHIP) plans) that required individuals to pay a monthly premium. Post-ACA, Medicaid eligibility was expanded in many states, but required premium contributions in some cases. To muddy the waters 
further, marketplace coverage is sometimes fully subsidized by the government (i.e., the monthly premium is USD 0), but is still considered private. Another complicating factor is the "no-wrong-door" design of the portal. One objective of the portal was to make it easy for those seeking coverage to explore and obtain coverage anywhere on the spectrum from fully subsidized public coverage to unsubsidized marketplace coverage, depending on their eligibility. Thus, enrollees could begin their search for coverage expecting to be eligible for, say, subsidized private coverage, but end up qualifying for public coverage. All these issues - the dual meaning of the term marketplace, the blurry line between public and private coverage, and the no-wrong-door design of the portal - complicate the task of categorizing coverage type from survey data (Pascale et al. 2013).

Two major federal surveys that researchers and policymakers rely on for estimates of health insurance coverage are the Current Population Survey Annual Social and Economic Supplement (CPS) and the American Community Survey (ACS). In response to many of the measurement error issues noted above, after more than a decade of research and testing, the CPS was redesigned beginning with calendar year 2013 estimates (Pascale 2016; Pascale et al. 2016). In preparation for full implementation of the ACA in 2014, research was conducted to adapt the newly-redesigned CPS for marketplace coverage (Pascale et al. 2013). Research on adapting the ACS is ongoing and no ACA-specific changes have yet been made to the questionnaire; it is expected that respondents with marketplace coverage will report it as private, non-group coverage.

This study extends past research by measuring and comparing reporting accuracy of coverage type and the overall uninsured rate in the CPS and ACS in a post-ACA era. This is important, given the role of these two surveys in the research and policy arenas, the gaps in the literature on measurement error discussed above, and the relatively uncharted territory of reporting accuracy post-ACA. Two key aspects of the study are: (1) it uses survey data matched to enrollment records as a "truth source," and (2) the enrollment records cover multiple types of coverage, both public and private. Specifically, we examine two types of public coverage (Medicaid and a program called MinnesotaCare - a state-specific program for low-income families that charges a sliding-fee premium) and three types of private coverage (ESI, and non-group coverage within and outside the marketplace). This is a rare opportunity and gives us the chance to examine multiple dimensions of misreporting. The study extends research on reporting accuracy beyond Medicaid to address multiple types of public and private coverage. It also allows us to explore how misreporting of one type affects another. Specifically, most prior research has focused on the question of under-reporting: among those enrolled in coverage type $\mathrm{X}$ according to records, how many fail to report coverage type $\mathrm{X}$ in a survey? This design allows us to go beyond that question and examine, for example, if coverage type $\mathrm{X}$ was not reported, what coverage type, if any, was reported?

Data for this research come from the CHIME study (Comparing Health Insurance Measurement Error), a reverse record check study in which enrollment records were used to sample households with individuals known to be enrolled in various types of private and public coverage. Phone numbers associated with these households were randomly assigned to either the CPS or ACS health insurance module, and a brief split panel household-level telephone survey was conducted in the spring of 2015. Person-level matching was conducted to assess agreement between the survey data and the enrollment 
records for individuals in the household. In terms of time period of coverage, both the CPS and ACS ask about coverage on the day of the interview, rendering a point in time (PIT) estimate. (The CPS also collects data on coverage from the beginning of the prior calendar year up to the interview date, but because the ACS is limited to point-it-time, this analysis focuses only on PIT estimates).

The ultimate objective of the current analysis is to use enrollment records from a private health plan as a "truth source" to evaluate and compare reporting accuracy of both coverage type and the net uninsured estimate at a point in time in the CPS and ACS. Three different reporting accuracy metrics were analyzed: under-reporting (enrollment records indicated coverage type $\mathrm{X}$, but coverage type $\mathrm{X}$ was not reported in the survey); overreporting (coverage type $\mathrm{X}$ was reported in the survey, but it could not be verified in the enrollment records); and prevalence (the estimate of coverage type $\mathrm{X}$ from the enrollment records compared to the estimate from the survey).

\section{Methods}

The CHIME study was multi-faceted and addressed several research questions, only some of which are the focus of this article. Below are highlights of the methodology relevant to this analysis, and complete study design details are documented in Fertig et al. (2018). As was noted in that paper, a common critique of record linkage studies is that administrative records come with their own sources of error. To mitigate this, we worked in close collaboration with informatics staff affiliated with the health insurer to maximize the veracity of the records data (e.g., by carefully examining and resolving duplicate records). Thus, we label the records as the "gold standard" and use terms like "accuracy" and "truth." However, we emphasize the quotes around these terms and we invite skeptical readers to interpret the results as simply a comparison of two data sources.

\subsection{Sample}

The study surveyed a stratified random sample of households known to have health insurance through one large regional insurer in the Midwest. At the time of data collection, the private health insurer offered all the major categories of private and public coverage: ESI, non-group outside the marketplace, marketplace coverage, and two types of public coverage: Medicaid and MinnesotaCare. The health insurer provided a sample of Minnesota households from each of these five coverage types or strata, as well as a "transition" strata of policyholders who switched from ESI to public or vice versa in 2014. Households were included in the sample if the home address was in Minnesota, the enrollment records included a phone number, and at least one eligible policyholder resided in the household. Eligible policyholders were under age 65 and belonged to one of the coverage type strata in December 2014, when the sample was drawn. At the time of the sample draw, there were just under 700,000 individual members across the six strata (see Table 1), and of those, roughly 270,000 were eligible policyholders. Among these policyholders, roughly 175,000 had a telephone number, and after removing duplicate addresses there were about 130,000 unique eligible households from which to sample.

To determine total sample size we began with the budget, which we estimated would support data collection yielding 5,000 completed household interviews. We assumed a 


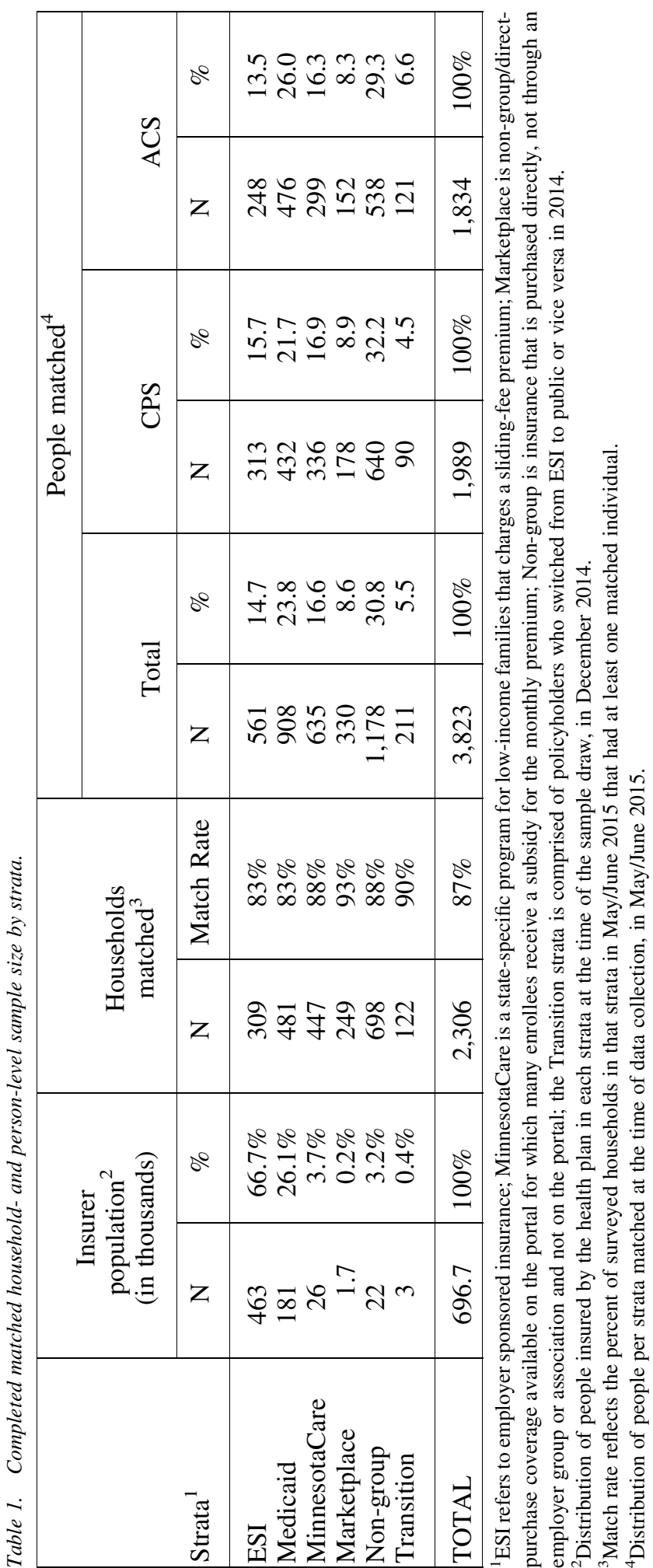


response rate of about $30 \%$ and calculated we would need an initial sample size of 16,000 phone numbers. To determine how to allocate the sample across strata, we made assumptions about average household size and rates of under-reporting to conduct a power analysis with a threshold of 0.80 . We aimed for a minimum detectable difference of about 2.5 percentage points in each stratum, but in two strata (marketplace and MinnesotaCare) the number of available households in the universe was insufficient to meet this goal. Thus, we sampled the entire universe for these two strata, but the minimum detectable difference for them was somewhat higher than ideal (about 5 percentage points for each).

The health insurer required that an advance letter be mailed informing eligible households that they were partnering with the Census Bureau on a study. The letter invited members who did not wish to participate to opt-out by calling in or writing to the health insurer's call center. Based on assumptions about opt-outs and bad address rates, the health insurer mailed a total of 22,000 advance letters with a goal of achieving 16,000 phone numbers of eligible and willing policyholders. We allowed about a month between the mail date of the letter and delivery of the final sample of members to Census; less than $6 \%$ of the letters were returned as a bad address or resulted in an opt-out. The final sample of 16,000 phone numbers was delivered to the Census Bureau in December 2014, for processing and preparation for data collection.

\subsection{Data Collection}

All interviews were conducted by Census Bureau telephone interviewers at the Hagerstown, Maryland, facility. Average administration time was 17 minutes. Data collection occurred during two distinct but consecutive three-week field periods from May 20 until June 28, 2015. In order to minimize interviewer effects, interviewers were assigned to one of two groups: each interviewer group was initially trained on either the ACS or CPS health insurance module and worked exclusively on that version during the first field period. At the end of the first field period, the interviewers switched questionnaire treatments and received a brief training on the new health insurance module and worked exclusively on that version during the second field period. We collected data from 2,660 households representing 6,644 people and a response rate of $22 \%$ using an adapted version of AAPOR RR 4 (American Association of Public Opinion Research 2016). Specifically, the RR4 reduces the denominator by including only a proportion of households with unknown eligibility (i.e., "unknown if occupied/household" and "other/ unknown"). In the CHIME data collection, households of unknown eligibility included "unknown if occupied/household", "other/unknown", noncontacts, and "other" dispositions because these four groups were comingled.

After completion of the survey, in August 2015, the health insurer sent the Census Bureau a second file with data on every individual insured by the health insurer $(\mathrm{n}=35,591)$ in the 16,000 households from the original sample, including enrollment data reflecting coverage in May and June of 2015. This ensured that the time period of coverage asked about in the survey was perfectly aligned with the time period indicated in the records.

We used a computer-match algorithm to link the enrollment person-record to its corresponding survey person-record for several reasons. First, there was some lag time 
between the date the sample was selected and the interview date, so the original phone numbers could have been reassigned to a different household and/or the insured member(s) could have moved out of the household. Second, among phone numbers that matched at the household level, it is possible that not all household members were insured by this health insurer. Thus the person-level computer match was conducted using variables on both datasets: phone number, name, sex, date of birth and address. Clerical review of borderline matches was also conducted to ensure accurate matches. The number of matched households and people by strata are shown in Table 1. We were able to match at least one person in $87 \%$ of surveyed households. Fifty-eight percent of individuals with survey data were matched to an enrollment record. However, as members of one household may be covered by different health plans (or some may be covered and others not), many of the individuals in the survey data may not have a match in the enrollment records from this health plan. All households with at least one matched individual $(\mathrm{n}=2,306)$ were included in the CHIME study.

\subsection{Nonresponse Analysis}

To assess whether the matched households were different from non-matched and nonrespondent households, we compared characteristics from the enrollment records in households with at least one matched person $(n=2,306)$ to households where no members were matched $(n=13,694)$ - either because no one in the household responded to the survey $(\mathrm{n}=13,340)$ or because there was a completed interview for the household but no person-record matched to the enrollment records $(\mathrm{n}=354)$.

As detailed in Fertig et al. (2018), compared to non-matched households, in matched households the policyholder was older (41.6 versus 34.5 years old, $\mathrm{p}<0.001$ ), was more likely to have moderate health risk $(47 \%$ versus $43 \%, \mathrm{p}<0.001)$ and less likely to have low health risk or be a healthy user $(27 \%$ versus $33 \%, \mathrm{p}<0.001)$, and there were fewer children $(0.5$ versus $0.7, \mathrm{p}<0.001)$ enrolled with the insurance company. The percent of female policyholders (51\%) and the number of adult members of the household (1.4) was the same for both groups.

\subsection{Demographics Across Treatment Groups}

Demographic characteristics of matched individuals were compared across treatments and for most characteristics there were no significant differences (see Appendix A, Subsection 7.1). The exceptions were that, compared to CPS individuals, ACS individuals were more likely to reside in households with five or more persons, were slightly more likely to be Hispanic or other race, and were more likely to have a family income that is 139-199\% of the federal poverty level (FPL). We adjust for these demographic differences across treatment arms in our analysis. Specifically, we run logistic regression models to determine whether the difference in reporting accuracy for CPS and ACS respondents was statistically significant when controls for family size, race/ethnicity, and family income were included in the model. We also used the coefficient estimates from these models to predict the likelihood of accurate reporting for ACS respondents if they had the same characteristics as CPS respondents (Tables 2 and 3 present ACS adjusted results; see Appendix B (Subsection 7.2) for CPS and unadjusted ACS results). 


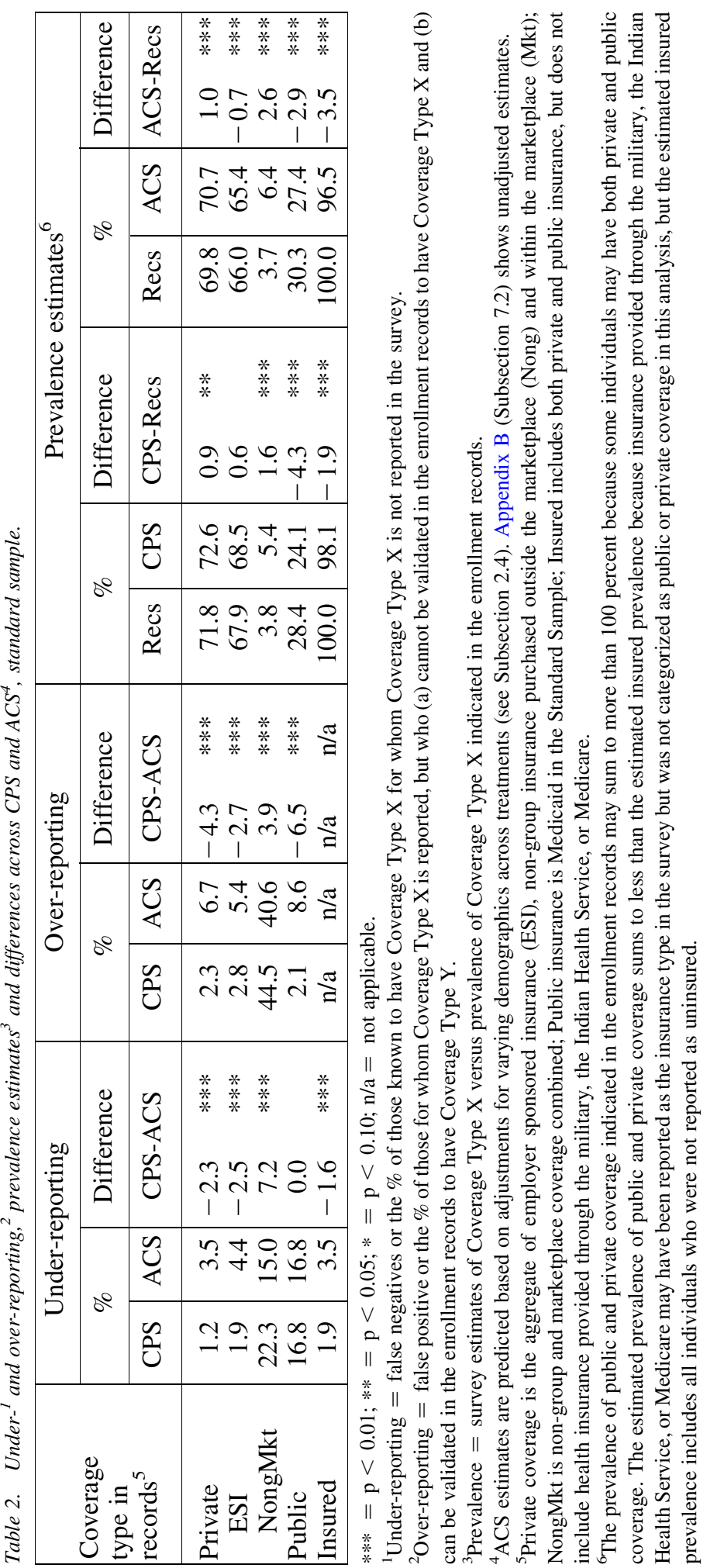




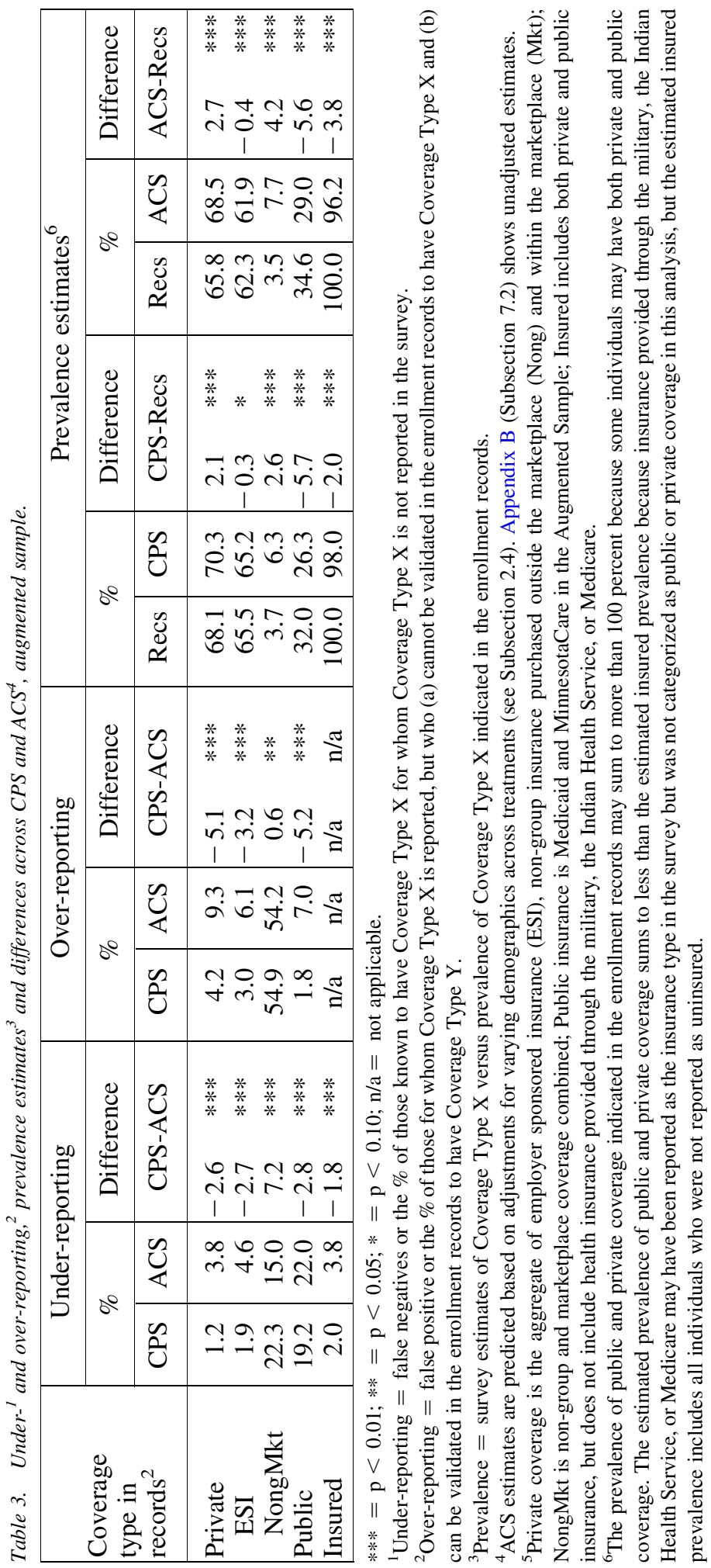




\subsection{Weights}

Our sample distribution across strata was driven by the goal of maximizing the ability to detect differences across treatments in reporting accuracy. Thus, by design, the distribution of sample across strata does not reflect any particular population. For the analysis dataset to be a useful reflection of a given population, we followed the only precedent we know of (Davern et al. 2008) and created weights to make the coverage type distribution match that of the original sampling frame - that is, the distribution of the total population of the health insurer (Table 1, second column). Because distributions were not identical in the CPS and ACS, we created separate weights for each arm. All results are presented as weighted percentages of the population.

\subsection{Questionnaires}

To set the context for the health insurance series of questions, the CHIME survey instrument began with a subset of items included in both the CPS and ACS on demographics, labor force and unearned income. The question wording of these three modules was identical across treatments, and after the unearned income module, half the respondents were randomly assigned to the CPS health insurance module and the other half to the ACS health insurance module.

Under both the CPS and ACS survey designs, a single household respondent is asked to answer health insurance questions for all household members. However, there are some key differences in the modules. First is with regard to structure. The CPS begins with general questions on source or type of coverage and then narrows down to capture the needed detail, while the ACS asks directly about discrete types of coverage. See Figure 1 for an abbreviated version of the questions, and see Appendix C (Subsection 7.3) for the complete health insurance modules. A second key difference is with regard to detail. The CPS includes questions that enable non-group coverage obtained outside the marketplace to be distinguished from marketplace coverage (see items 11-13 in Figure 1), and it includes questions to distinguish Medicaid from MinnesotaCare (see items 9-13 in Figure 1), while the ACS questions do not capture these details. Thus for all ACSCPS comparisons, we aggregate non-group and marketplace coverage into a single category.

\subsection{Categorizing Coverage Type}

While categorizing a respondent's source of coverage is straightforward in the ACS given the module's structure, the CPS is considerably more complicated. A separate analysis of the CPS exploited the enrollment records in the CHIME study to guide an algorithm for classifying coverage type. Answers to questions about features of the coverage (such as source, type of government/state plan and name of government/state program), and questions about the marketplace, premiums, and subsidization carefully evaluated (Pascale et al. 2018b) and used to classify the coverage into ESI, non-group, marketplace or public coverage (Pascale et al. 2018a). Once we had these disaggregated categories for the CPS, we created semi-aggregated categories in the CPS to match the ACS categories, and finally created aggregated private and public categories for a comparative analysis on the following individual and aggregated categories of coverage:

1. Private (ESI and/or non-group and/or marketplace coverage)

2. Public coverage (Medicaid and/or MinnesotaCare) 


\section{Employer-sponsored insurance (ESI)}

\section{Non-group and/or marketplace coverage}

\section{Uninsured}

\subsection{Analysis Samples and Monthly Premium Contributions}

The MinnesotaCare program provided us the opportunity to explore reporting accuracy for a public program that requires enrollees to contribute to the monthly premium.

CPS
Logic Check 1: If disabled or age $=65+\rightarrow 1$; else $\rightarrow 2$

1. Are you covered by Medicare?

- $\quad$ Yes $\rightarrow 14$

- $\quad$ No $\rightarrow 2$

2. Are you NOW covered by any type of health plan?

- Yes $\rightarrow 3$

- No $\rightarrow$ Qs on Medicaid and other public plans; verify currently uninsured $\rightarrow 18$

3. Is it provided thru a job, govt, or other way?

- Job $\rightarrow 6$

- Government $\rightarrow 4$

- Other way $\rightarrow 7$

4. Is that plan related to a JOB with the government?

- Yes $\rightarrow 6$

- $\mathrm{No}^{\rightarrow} 5$

5. Is that Medicaid/CHIP, Medicare, military, other?

- Medicaid/CHIP/other/DK $\rightarrow 9$

- Military $\rightarrow$ [type of military plan] $\rightarrow 10$

- Medicare $\rightarrow 14$

6. Is the plan related to military service in any way? [if yes, type of military plan] $\rightarrow 10$

7. How is it provided - parent/spouse, direct, other?

- Parent/spouse/direct $\rightarrow 10$

- $\quad$ Other $\rightarrow 8$

8. Is it thru former emp, union, group, assn, school?

- Former emp/union/group/assn/school $\rightarrow 10$

- Other $\rightarrow 9$

9. What do you call the program?

- Medicaid

- Medical Assistance

- Indian Health Service

- MinnesotaCare

- Minnesota Comprehensive Health Association

- PMAP

- Healthcare.gov

- Plan through MNsure

- Other government plan

- Other (please specify)

$\rightarrow 11$

10. Who is the policyholder?

[If direct in Q7 $\rightarrow$ 11; else $\rightarrow$ 14]

11. Is that coverage thru the marketplace?

12. Is there a monthly premium? [if yes $\rightarrow 13$; else $\rightarrow 14$ ]

13. Is the premium subsidized based on family income?

14. [Questions on past months of coverage]

15. Any [other] coverage Jan 2014 till now?

- Yes $\rightarrow$ loop thru series again, starting with 3

- No $\rightarrow$ Logic Check 2 for next person on roster

Logic Check 2: For this next person, if any coverage was already reported, start with Q15; else start with Logic

Check 1; If no more people on roster $\rightarrow E N D$
ACS

1. Are you currently covered by health insurance through a current or former employer or union?

- Yes

- $\quad$ No

2. Are you currently covered by health insurance purchased directly from an insurance company?

- Yes

- No

3. Are you currently covered by Medicare, for people age 65 or older or people with certain disabilities?

- Yes

- No

4. Are you currently covered by Medicaid, Medical Assistance, or any kind of government-assistance plan for those with low incomes or a disability?

- Yes

- No

5. Are you currently covered by TRICARE or other military health care?

- Yes

- No

6. Are you currently covered through the Veteran's Administration?

- Yes

- $\mathrm{No}$

7. Are you currently covered through the Indian Health Service?

- Yes

- No

8. Are you currently covered by any other health insurance or health coverage plan?

- Yes $\rightarrow$ (specify name of health care plan)

- No 
MinnesotaCare began in 1992 as a state-subsidized public health insurance program, where low-income households that do not qualify for Medicaid pay a subsidized monthly premium based on their income. As such, MinnesotaCare could function as a kind of proxy for public programs that require premium contributions in other states (such as the Children's Health Insurance Program and some Medicaid expansion participants). There is wide variation in the number of public programs within a given state, and complex rules for many of these programs regarding eligibility and premium contribution requirements. Fertig et al. (2018) includes a table of each state's public programs and premium contribution requirements as of August 2016. At that time, a total of 16 states offered only public programs that do not require a monthly premium contribution; 21 states offered at least one program that required a monthly premium contribution for at least some enrollees; and 14 states offered at least one public program that required a monthly premium contribution for all enrollees. In total, more than $69 \%$ of states offered one or more public program that required a monthly premium contribution for at least some, if not all, enrollees.

To gain insight into this diverse landscape, we exploit the presence of MinnesotaCare enrollees in the CHIME sample by presenting all results for two different analytic samples. The "Standard" sample excludes individuals with only MinnesotaCare ( $=657)$ and the "Augmented" sample includes those with MinnesotaCare. Appendix D (Subsection 7.4), displays the sample size and distribution for both samples. While we cannot predict reporting accuracy for all states with this study, we offer results from these two samples as a reasonable approximation of upper and lower bounds of reporting accuracy across states, depending on the structure and complexity of public programs within the state. In other words, the Standard sample results are meant to approximate reporting accuracy in states where Medicaid and other public program offerings do not require premium contributions. The Augmented sample is meant to represent reporting accuracy in states with a nontrivial number of individuals enrolled in public programs that require a premium contribution.

Finally, we omitted any individuals from the analytic sample for the current study if they did not have coverage at the time of the interview according to the enrollment records $(\mathrm{n}=130)$. Because our sample was selected in December 2014 but the interview was conducted in May/June 2015, we cannot discern whether an individual with no coverage in the enrollment records at the time of the interview was uninsured or insured with another company. Thus, our Standard sample contained 3,036 person-records and the Augmented sample contained 3,693 person-records.

\subsection{Reporting Accuracy Metrics}

We use three different metrics to evaluate reporting accuracy. First is under-reporting (aka false negatives): the percent of people known to have Coverage Type X (according to enrollment records) for whom Coverage Type $\mathrm{X}$ is not reported in the survey. Second is the other side of the coin or over-reporting (aka false positives): the percent of people for whom Coverage Type $\mathrm{X}$ is reported, but who could not be validated in the enrollment records to have Coverage Type $\mathrm{X}$. For the third metric, we compare the survey estimate of Coverage Type $\mathrm{X}$ to the prevalence of Coverage Type $\mathrm{X}$ indicated in the enrollment records. 
The over-reporting metric is somewhat compromised by our study design. Because we have enrollment records from only a single insurer, we cannot say with certainty that a report of Coverage Type $\mathrm{X}$ that cannot be validated in our records of Coverage Type $\mathrm{X}$ is truly an over-report. It could be a false positive, or it could be a legitimate report of Coverage Type $\mathrm{X}$ from a different insurer. However, one strength of our study design is that we have enrollment records on a broad range of coverage types. Therefore, among those for whom Coverage Type $\mathrm{X}$ was reported but could not be validated as Coverage Type $\mathrm{X}$ in our records, we can examine how often it could be validated as Coverage Type $\mathrm{Y}$ in our records.

\section{Results}

As discussed in the methods section, this study was conducted as an experiment, using only a subset of the data collection and processing systems used to produce the official CPS and ACS estimates. We use the term "survey" as a convenient shorthand to mean "health insurance questionnaire module." That is, all results presented reflect the impact of only the questionnaires; the effects of editing, imputation and other aspects of the processing system are not assessed in this study.

\subsection{Standard Sample}

We begin with results for the three metrics for all four categories of individual and aggregated coverage types, as well as the uninsured (see Table 2). The left-most panel shows results for under-reporting. For example, the first row indicates that among those with any kind of private coverage according to the records, no private coverage was reported for $1.2 \%$ of those in the CPS treatment and $3.5 \%$ of those in the ACS treatment. In both survey treatments, levels of under-reporting varied by coverage type and were fairly low (below 5\%) for ESI, private and insured, and higher (15-22.3\%) for non-group/marketplace and public. For public coverage the under-reporting was identical across surveys (at 16.8\%). For other coverage types the differences across surveys were generally small but statistically significant and varied by coverage type. For ESI, private and insured, under-reporting was lower in the CPS than the ACS, by 1.6-2.5 percentage points. For non-group/marketplace the ACS under-report was lower than the CPS by 7.2 percentage points. Among those with any kind of private or public coverage according to the records, no coverage at all was reported for $1.9 \%$ of CPS enrollees, and $3.5 \%$ of ACS enrollees.

Turning to over-reporting in the center panel, the first row indicates that among those for whom private coverage was reported, $2.3 \%$ could not be validated in the CPS records to have private coverage, and $6.7 \%$ could not be validated in the ACS records. Generally, overreporting ranged from $2.1 \%$ to $8.6 \%$ across coverage types with the exception of non-group/marketplace, which was dramatically higher - over $40 \%$ in both surveys. Across coverage types, CPS-ACS differences were still fairly small in magnitude but statistically significant. Within type of private coverage, over-reporting of non-group/marketplace was $44.5 \%$ and $40.6 \%$ in the CPS and ACS, and over-reporting of ESI was only $2.8 \%$ and $5.4 \%$ in the CPS and ACS (respectively). Among those for whom public coverage was reported, over-reporting in the ACS was higher than in the CPS $-8.6 \%$ and $2.1 \%$, respectively.

In terms of overall prevalence (right-most panel) - how close the survey estimate came to the population prevalence - estimates varied across coverage types and surveys, but all 
were within about one to four percentage points of population prevalence. Private and nongroup/marketplace coverage were slightly over-estimated in both surveys, and public coverage was slightly under-estimated in both. Regarding the uninsured, in both surveys people known to have some type of coverage were reported as uninsured $-1.9 \%$ in the CPS treatment and $3.3 \%$ in the ACS treatment.

\subsection{Augmented Sample}

Results on under-reporting in the Augmented sample (which includes MinnesotaCare enrollees in the public coverage category) map closely to the Standard sample results in terms of overall levels and CPS/ACS differences, with the exception of public coverage (see Table 3, the left-most panel). Overall levels of under-reporting for public coverage were higher in both surveys in the Augmented compared to the Standard sample. Also, while under-reporting was the same across surveys in the Standard sample (at 16.8\%), in the Augmented sample the CPS resulted in less under-reporting (19.2\%) than the ACS (22.0\%).

With regard to over-reporting (center panel), the most notable difference between the Standard and Augmented samples was in non-group/marketplace coverage, which increased by more than ten percentage points in both surveys - from 44.5 to 54.9 percentage points in the CPS and from 40.6 to 54.2 percentage points in the ACS. This shift reduced the CPS-ACS differential; in the Standard sample, CPS over-reporting was 3.9 percentage points higher than ACS but in the Augmented sample, CPS over-reporting was only 0.6 percentage points higher than ACS. Over-reporting of public coverage decreased in both surveys but more so in the ACS than the CPS. In the ACS, overreporting went from $8.6 \%$ in the Standard sample down to $7.0 \%$ in the Augmented sample, and in the CPS over-reporting went from $2.1 \%$ to $1.8 \%$.

In terms of prevalence (right-most panel of Table 3), across both surveys, patterns were similar when moving from the Standard to the Augmented sample. Specifically, private coverage was over-estimated more in the Augmented than the Standard sample, and this was driven by non-group/marketplace coverage (not ESI) across both surveys. For public coverage both surveys underestimated coverage in both samples, but the gap widened in the Augmented compared to the Standard sample, and more so in the ACS than the CPS. In the CPS, the under-estimate of public coverage went from 4.3 percentage points in the Standard sample to 5.7 percentage points in the Augmented sample. In the ACS, the underestimate went from 2.9 percentage points in the Standard sample to 5.6 percentage points in the Augmented sample, putting it on par with the CPS over-estimate.

\subsection{Non-Group/Marketplace Coverage}

Results for non-group/marketplace coverage were something of an anomaly. Levels of under- and over-reporting were lower in the CPS than ACS for all coverage types except this one, and levels of over-reporting for non-group/marketplace were markedly higher than all the other coverage types in both surveys. To explore this further we break down the under-reporting results into more detail. Because the enrollment records indicate nongroup versus marketplace coverage, regardless of which survey respondents were assigned to, we can examine under-reporting results separately for non-group and marketplace enrollees (see Table 4, left and right panels, respectively) for both CPS and ACS. We also 
examine not just under-reporting but presumed misreporting - that is, among non-group and marketplace enrollees whose coverage was not reported as non-group/marketplace, how often was a different type of coverage or no coverage reported? In Table 4 we show the percentage of enrollees for whom the correct coverage type was reported and label that the "Target" row. Note this is simply a different expression of under-reporting; rather than show the percentage who did NOT report the known coverage type (as in Tables 2 and 3), in Table 4 we show the percent who DID report the known coverage type. The next three rows indicate that non-group/marketplace coverage was NOT reported, but a different coverage type (ESI, public or other) was reported. The final row indicates how often no coverage of any type was reported.

Results for the ACS show that levels of reporting the Target coverage type are roughly equivalent among non-group and marketplace enrollees (85.6\% and 83.6\%, respectively). However, in the CPS, levels of reporting the Target coverage type are much lower among marketplace enrollees $(62.9 \%)$ than non-group enrollees $(78.5 \%)$. With regard to NonTarget reporting, in the ACS it is roughly evenly split between ESI and public among both non-group and marketplace enrollees (e.g., among non-group enrollees, ESI and public coverage reporting is $6.4 \%$ and $5.4 \%$, respectively). In the CPS, however, among nongroup enrollees the most common Non-Target coverage is by far ESI (15.3\%), and public and other/unspecified are roughly evenly split (3.2\% and 2.4\%). Among CPS marketplace enrollees, public is the most common Non-Target coverage type reported (18.5\%), while ESI and other/unspecified are roughly evenly split (9.0\% and 8.4\%). Finally, although the ACS generated higher levels of Target reporting for both non-group and marketplace enrollees, both these types of enrollees were more likely to be misreported as uninsured in the ACS than in the CPS. Among non-group enrollees, $0.6 \%$ and $1.8 \%$ are misreported as lacking coverage in the CPS and ACS, respectively, and among marketplace enrollees $1.1 \%$ and $2.1 \%$ are misreported as lacking coverage in the CPS and ACS.

We also explore over-reporting in more detail (see Table 5). Because we begin with the universe of respondents who reported non-group/marketplace, and the ACS does not distinguish between these two coverage types, we cannot split out results for non-group from marketplace. However, among those for whom non-group/marketplace coverage was reported, we can show how often non-group/marketplace coverage could be validated in the records, and how often non-group/marketplace could not be validated but a different type of coverage (ESI or public) could be validated instead. Note that results in the Target row are, again, simply a different expression of over-reporting results already shown in Table 2. For example, Table 2 shows the percentage of reports that could not be validated in the CPS is $44.5 \%$, and Table 5 shows the percentage of reports that could be validated is $55.5 \%$, and these two metrics sum to 100 (i.e., the universe of non-group/marketplace reports is accounted for when we sum under-reports and Target reports). What is new in Table 5 is the Non-Target results. These findings show that in the CPS Standard sample, among the non-group/marketplace reports that could not be validated to be the Target coverage type, most $(36.2 \%)$ were validated to have ESI coverage and the remainder had public $(8.3 \%)$. In the ACS, however, the Non-Target cases were roughly evenly split between ESI and public (20.5\% and $19.4 \%$, respectively). In the Augmented sample, the addition of the MinnesotaCare sample shifts these distributions, with both the CPS and ACS having more reports of non-group/marketplace being validated as public coverage. 


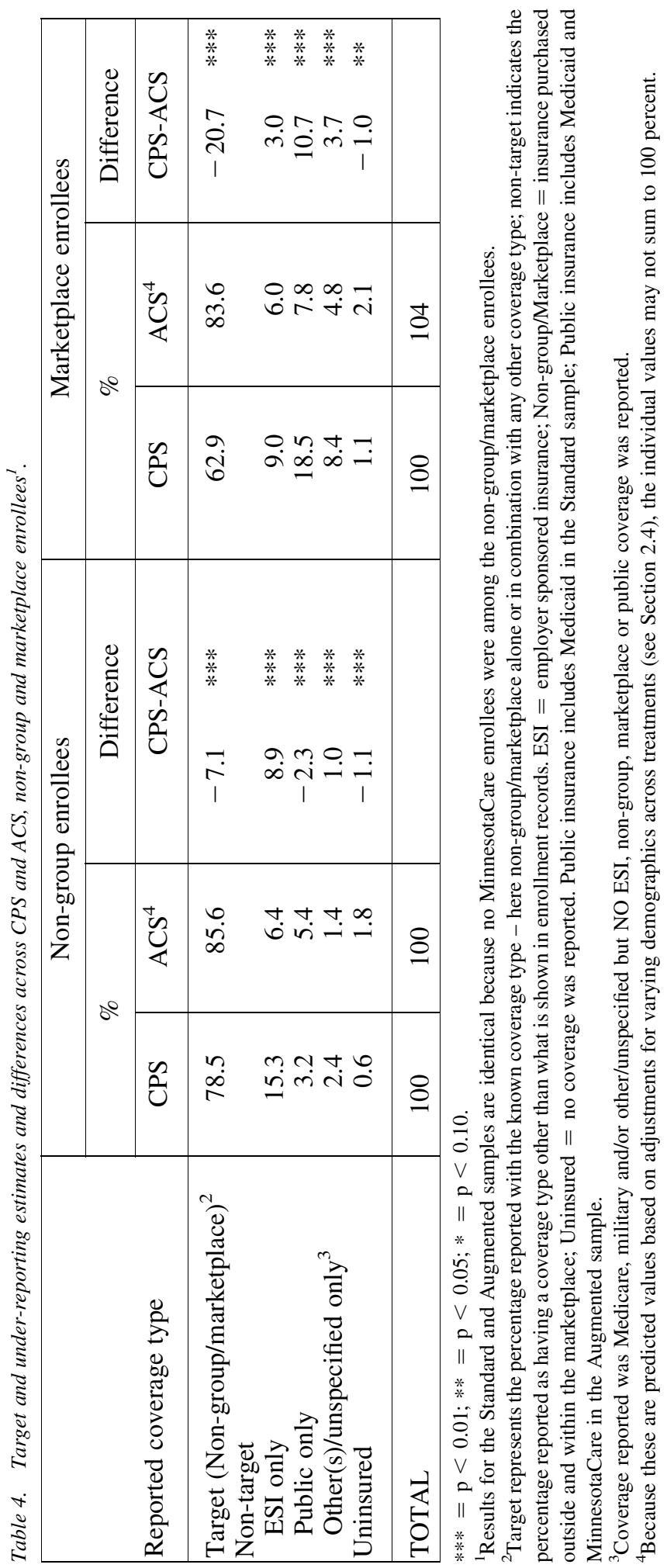




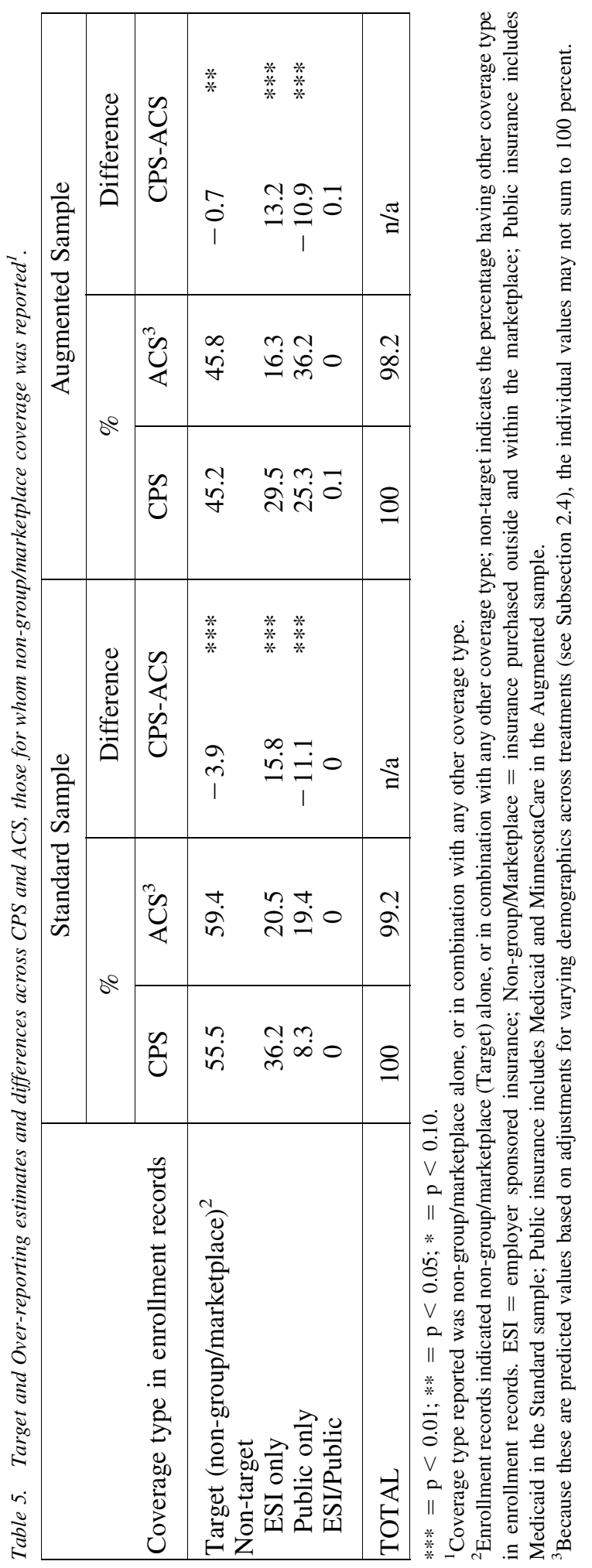




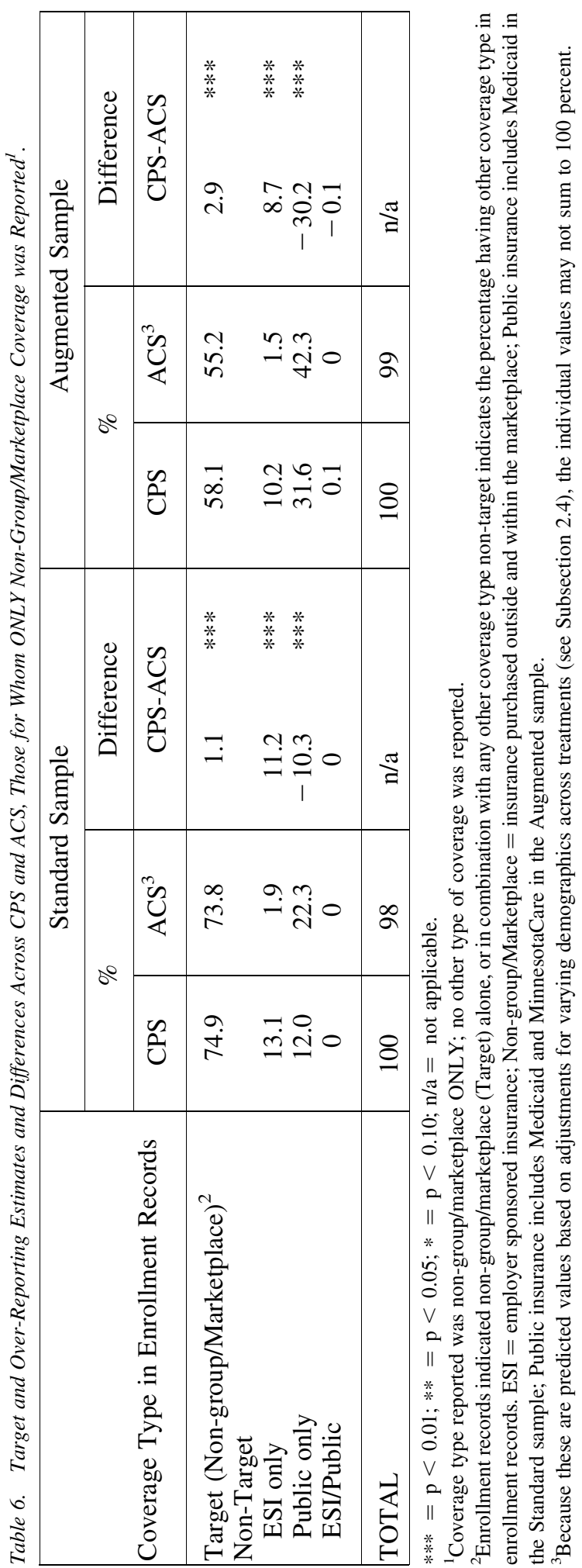


We take the non-group/marketplace results one step further to address the research suggesting that noncomprehensive non-group plans (e.g., dental and vision plans) may account for much of the observed over-reporting of non-group/marketplace coverage. Table 6 mimics Table 5 except that we limit the sample to those for whom ONLY nongroup/marketplace coverage was reported (versus those for whom non-group/marketplace was reported in combination with one or more other types of coverage). Thus, for example, Table 6 EXCLUDES those who report having ESI and non-group/marketplace when they actually have ESI and a dental plan. Results show a fairly dramatic shift. Over-reporting (100 minus the validated reports of coverage shown in the Target row) drops by almost 20 percentage points in the CPS and by almost 15 percentage points in the ACS in the Standard sample. The same pattern is observed in the Augmented sample but the magnitude of the drop in over-reporting is somewhat lower. Further, when we limit the sample to those for whom only non-group/marketplace coverage was reported in the Standard sample (Table 6), those validated to have ESI drops by 23 percentage points in the CPS and by almost 19 percentage points in the ACS and those validated to have public increases by roughly 3-4 percentage points for both surveys compared to Table 5. The pattern is similar in the Augmented sample: those validated to have ESI drops by 19 percentage points in the CPS and by almost 15 percentage points in the ACS between Tables 5 and 6, and those validated to have public increases by roughly 6 percentage points for both surveys.

\subsection{Uninsured}

Finally, we examine how these patterns of over- and under-reporting by coverage type affect the measure of the uninsured, and how this varies across surveys (see Table 7). Columns indicate the coverage type according to the records, and rows indicate the reported coverage type - either Target, Non-Target or Uninsured. Public enrollees are more likely to be misreported as uninsured than private enrollees, across both survey treatments, by several fold. In the CPS, $5.0 \%$ of public versus only $0.8 \%$ of private enrollees are reported to have no insurance; in the ACS the rate is $6.6 \%$ for public and $2.2 \%$ for private. Across types of private coverage, results are fairly consistent; reports of no coverage are within a percentage point of each other for both surveys. For example in the CPS, uninsured rates for ESI, non-group/marketplace, non-group alone, and marketplace alone is $0.8 \%, 0.7 \%, 0.6 \%$ and $1.1 \%$, respectively. In terms of differences across surveys, for public and private coverage overall, and for each component of private coverage, the uninsured rate is higher in the ACS than in the CPS, by 1.0 to 1.6 percentage points across coverage types.

\section{Discussion}

\subsection{Moving Parts: The Inter-Relationship between Misreporting and Coverage Type Prevalence}

There are several moving parts in a study like this. Among them are differences in the surveys' capacity to elicit true positives and avoid false positives, variation in over- and under-reporting across coverage types in both surveys, and the prevalence of the various coverage types in the population. While all of these are at play in the findings, one constant is the sheer dominance of ESI relative to other coverage types. For our particular insurer's 


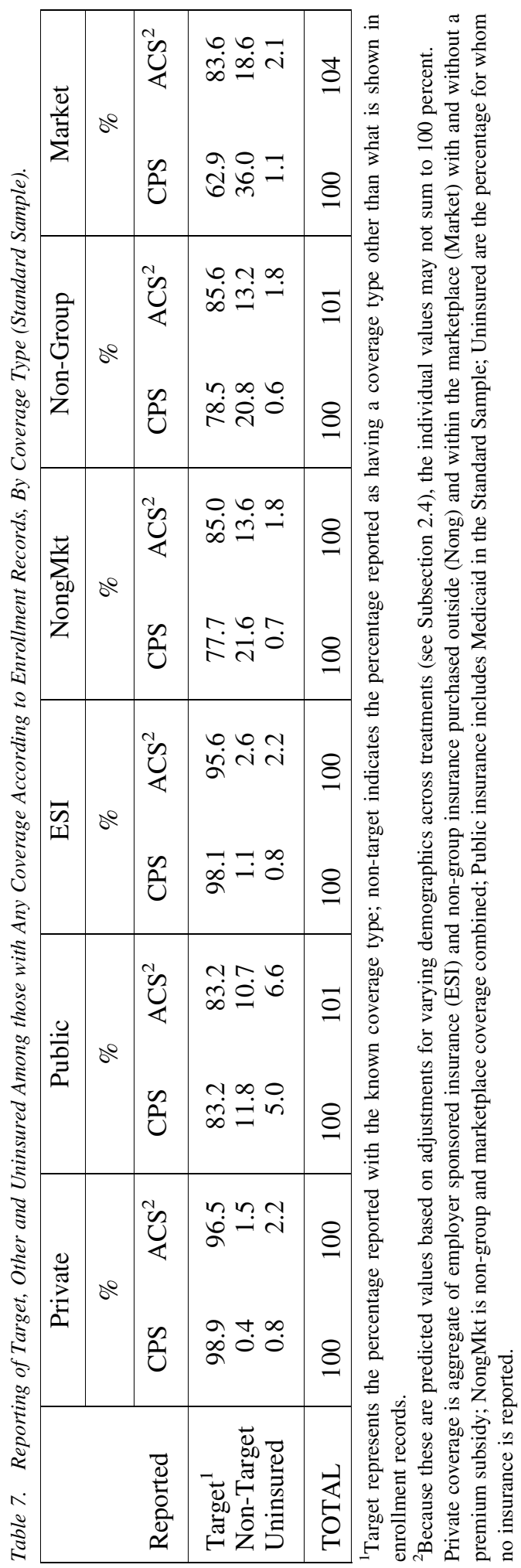


population, the prevalence of ESI was $67 \%$, public was $30 \%$ and non-group/marketplace was 3.4\% (see Table 1). This distribution means that, consistent with Davern et al. (2008), reporting patterns of ESI enrollees have the greatest effect on the metrics for all the other coverage types. Another constant is simply the logic of aggregation. The private coverage metrics are a function of ESI and non-group/marketplace together, so respondents could report the wrong type of private coverage (e.g., ESI enrollees could misreport their coverage as non-group/marketplace, or vice versa), and metrics for the individual coverage types would be affected but the overall private metrics would not. Both of these factors played out in our results. For example, under-reporting of ESI was fairly low in both surveys (1.9\% and 4.4\% in CPS/ACS, Table 2), but for non-group/marketplace it was higher $(22.3 \%$ and $15.0 \%)$. The low prevalence of non-group/marketplace coverage, the high prevalence of ESI combined with its low rate of under-reporting, and the fact that respondents could interchange ESI and non-group/marketplace coverage for the overall private coverage metric meant the impact of non-group/marketplace under-reporting, while high, had a negligible effect on private coverage metrics. Indeed, under-reporting for the aggregated private coverage type category $(1.2 \%$ and $3.5 \%$ in CPS/ACS) was lower than for either of the two components of private coverage.

This kind of inter-play was also evident in the CPS-ACS differences. For example, on under-reporting, the ACS did better than the CPS for non-group/marketplace (by 7.2 percentage points, Table 2), but worse than the CPS for ESI (by 2.5 percentage points), and the surveys were identical on public coverage. For both aggregated categories of private coverage and the insured, the CPS did better than the ACS. Thus, the improved metric for non-group/marketplace in the ACS was not enough to compensate for its lower metric for ESI, given the low prevalence of non-group/marketplace relative to ESI. In other words, higher under-reporting of ESI in the ACS versus the CPS is the main driver of the differences between the two surveys in both the private and uninsured rate. A similar pattern was observed in over-reporting. Rates for ESI and public were lower in the CPS than the ACS, and higher for non-group/marketplace coverage. Due in large part to the weight of ESI relative to other coverage types, over-reporting of private coverage was 4.3 percentage points lower in the CPS than the ACS.

In terms of the point estimate, the difference between the survey estimate and the population prevalence is a function of not only the relative prevalence of different coverage types and levels of under- and over-reporting, but the nature of misreporting. For example, under-reporting of public coverage was identical in the CPS and ACS, but overreporting of public coverage was a fair bit higher in the ACS than the CPS (by 6.5 percentage points, Table 2). However, the ACS under-estimated public coverage by 2.9 percentage points and the CPS under-estimated it by 4.3 percentage points. Thus, the lower over-reporting of public coverage in the CPS resulted in fewer false positives to make up for the false negatives, compared to the ACS. There is an additional nuance at work, which has to do with the difference in the Standard and Augmented samples. Recall that the Augmented sample includes MinnesotaCare enrollees, who contribute to the monthly premium based on a sliding scale. Where under-reporting of public coverage in the Standard sample was identical across surveys (Table 2), in the Augmented sample under-reporting in the CPS was lower than in the ACS (19.2\% versus 22.0\%, Table 3). Also, while over-reporting was still higher in the ACS versus CPS, the differential was 
reduced (6.5 percentage points in the Standard sample versus 5.2 percentage points in the Augmented). The combination means that in the Augmented sample, the ACS picked up fewer legitimate reports of public coverage than it did in the Standard sample, AND it gained slightly fewer over-reports. Thus, the net estimate of public coverage in the ACS compared to the population prevalence was no longer as close as it was in the Standard sample; indeed in the Augmented sample it was on par with the CPS.

\subsection{Effects of Public Coverage that Requires a Premium Contribution}

More generally, when moving from the Standard to Augmented sample, under-reporting was equivalent for all coverage types except public, which increased by about 2.5 percentage points in the CPS and about 5 percentage points in the ACS. This suggests that in states where public programs require the enrollee to contribute to the premium, underreporting goes up in both surveys, but more so in the ACS than in the CPS. In terms of over-reporting, the most pronounced difference between the Standard and Augmented samples was among those reporting non-group/marketplace coverage, where overreporting increased by about 10 percentage points in the CPS (from $44.5 \%$ to $54.9 \%$ ) and about 14 percentage points in the ACS. Because the only difference between the two samples is that the Augmented sample includes MinnesotaCare enrollees while the Standard sample does not, these results suggest that MinnesotaCare enrollees have a tendency to misreport their public coverage as non-group/marketplace coverage in both surveys, but more so in the ACS than in the CPS. With regard to overall prevalence, the gap between the survey estimate and population prevalence got slightly wider for private, public and non-group/marketplace coverage when moving from the Standard to the Augmented samples, and stayed about the same for ESI and uninsured. This pattern held for both surveys, but the size of the gap was slightly higher in the ACS than the CPS for private and non-group/marketplace and especially for public coverage. Again this suggests that in states where there is cost-sharing for public programs, measurement error will be slightly increased for private coverage (driven by non-group/marketplace) and public coverage compared to states where public programs have no premium cost-sharing, and that the ACS estimates will be somewhat more prone to measurement error than the CPS, particularly for public coverage.

\subsection{Non-Group/Marketplace Results}

Non-comprehensive plans - those that cover only a single service such as dental or vision - are common in the non-group market. Technically speaking, respondents should not report these non-comprehensive plans at all, because they are out of scope in the survey. Also because they are out of scope, they are not in the universe of plans that could be validated in the records. However, to the extent respondents are not paying attention to the "fine print" in the survey and report these non-comprehensive plans, they cannot be validated, and thus contribute to over-reporting. The large reduction in over-reporting when we eliminated those who reported non-group/marketplace in combination with another type of coverage (that is, the difference in the Target metrics when moving from Table 5 to 6) suggests that non-comprehensive plans could well be a major contributor to the over-reporting of non-group/marketplace coverage. In terms of misreporting, the 
finding that non-group enrollees misreport their coverage as ESI more in the CPS than in the ACS is curious (15.3\% versus $6.4 \%$, Table 4$)$. One possible explanation could reside with the self-employed who obtain coverage on the individual market but consider it a business expense. The CPS asks about coverage "through a job" while the ACS asks if coverage is through "a current or former employer or union." Some non-group enrollees may be inclined to select "job" in the CPS because the coverage is tangentially related to their self-employed status, which enables them to consider it a business expense. However, in the ACS when asked about coverage through an "employer or union" versus coverage "purchased directly from an insurance company," they may choose the latter. For these individuals the terms "employer/union" may signify more formal arrangements with a third party institution, which may not match the concept of their self-employment.

Marketplace coverage is relatively new in the landscape of health coverage options, and it is saddled with ambiguity with regard to self-reports in surveys. For instance, the very term "marketplace" can mean the portal through which coverage is obtained, and/or the marketplace coverage itself. There are also multiple other pathways to obtaining marketplace coverage, in addition to the portal (e.g., brokers). Furthermore, both public and private plans are available on the portal, some marketplace plans are fully subsidized, and some public plans charge a premium. Thus, any one question that could definitely establish marketplace coverage is elusive. The CPS and ACS surveys go about capturing marketplace coverage in very different ways. In the ACS, it is assumed that marketplace enrollees would report their coverage in response to the question asking about "health insurance purchased directly from an insurance company" (see Figure 1, second question). Indeed, $83.6 \%$ of marketplace enrollees did this (see Table 4). However, the ACS has not yet made any attempts to separate marketplace from non-group coverage. In the CPS, respondents are asked a series of questions about features of the coverage, such as general source (job, government/state), program name, portal, premiums and subsidies. For the reasons noted above, none of these individual questions alone determines coverage type. In a related research project, we used a supervised machine learning approach and enrollment records to guide an algorithm using these questions to classify coverage type in the CPS (Pascale et al. 2018a). There were multiple trade-offs and due to the high prevalence of public relative to marketplace coverage, for the small handful of ambiguous cases, we chose an algorithm that slightly favored public over marketplace classification. This choice could partially explain why, in Table 4, 18.5\% of known marketplace enrollees are shown as reporting public coverage, which, in turn, contributes to the Target marketplace metrics being lower than non-group (62.9 versus 78.5).

\subsection{The Uninsured Rate}

As noted earlier, the few existing studies that linked enrollment records with survey reports of both public and private coverage were conducted under very different conditions than our study, and comparisons with regard to coverage type are of limited use. The most relevant metric from these earlier studies would be false negatives of insurance: what percent of those with any kind of coverage according to the records were misreported as uninsured. Our study found overall uninsured rates of $1.9 \%$ and $3.5 \%$ in the CPS and ACS, respectively. Nelson et al. (2000) and Marquis (1983) found rates of 2.2\% 
and 3\%, respectively. Davern et al. (2008) found lower rates $(0.3 \%$ to $0.6 \%$ across coverage types), which could be partly explained by their inclusion of those over 65 (where coverage is near-universal), and their exclusion of proxy reports. In terms of CPSACS differences, one reason the ACS uninsured rate was 1.4 percentage points higher than the CPS could be the fact that the CPS series begins with a global yes/no question on any coverage at all, while the ACS does not. Several qualitative and quantitative studies indicate that a single household respondent sometimes has only limited knowledge about the details of other household members' coverage, and when confronted with a series of questions about specific coverage type, some respondents simply fail to report any coverage at all (Pascale 2009). Another key difference in the surveys is the "verification question." After a battery of questions on different types of coverage is asked, if no coverage is reported the CPS (and several other surveys) ask if it is correct that the person is uninsured, and if not the survey allows for collecting detailed information on the coverage. The ACS does not include this verification question. A final compounding problem in the ACS could be household size. The eight-question "laundry list" series is repeated for each household member, which risks respondent fatigue once the series is administered for, say, the fifth or sixth person, particularly if those individuals listed later in the household roster are more socially distant from the household respondent (e.g., unrelated housemates). This kind of respondent fatigue can result in a failure to report any coverage (Blumberg et al. 2004).

\section{Limitations}

There are several limitations that could influence the results and their generalizability. First, Minnesota is an atypical state in terms of demographics; compared to the U.S. as a whole, the state has a higher proportion of whites and those with a high school diploma and college degree. The state population has high rates of health insurance, high income, low unemployment and very low poverty relative to other states (U.S. Census Bureau 2016a, 2016b). Second is the fact that the study represents coverage from a single health insurance provider which, on its face, limits generalizability of the results. More specifically, however, with regard to the marketplace, the insurer's market share is relatively low. In 2014, the insurer served four percent of the "MNsure" market (the name for private marketplace plans in Minnesota), compared to $59 \%$ and $25 \%$ by the dominant insurers in the marketplace (Minnesota Department of Health 2018). Furthermore, the insurer's marketplace plans had higher premiums than most MNsure plans. It is possible that CHIME participants in the marketplace strata are more educated and financially secure than those in the marketplace population overall, and that these characteristics affect reporting accuracy. To investigate this, in related analysis (Call et al. 2018) we examine socioeconomic and health status characteristics associated with reporting accuracy. Third, the study design does not allow us to determine with certainty whether apparent false positives were truly inaccurate. That is, a report of coverage that could not be validated in the insurer's records could actually be accurate if the person had insurance from a different carrier. Finally, due to the relatively low response rate we cannot ascertain, beyond our simple nonresponse analysis, whether our results are biased due to differential response; it could be that those well aware of their insurance status would be the most likely to respond. 


\section{Conclusions}

The scant studies thus far that have examined reporting accuracy across a range of coverage types suggest private coverage is over-reported and public coverage is under-reported (Davern et al. 2008; Nelson et al. 2000). Our findings are generally consistent with these earlier studies, but for the first time we provide reporting accuracy metrics based on two major national survey instruments in a post-ACA era, and we compare the two surveys for both individual and aggregated coverage types. Because there is such an established literature on the role of the questionnaire in measurement error of health insurance estimates, and the ACA represents a major shift in the landscape of the U.S. health system, we offer these metrics as a baseline. That is, we reserve judgment on whether the metrics indicate high or low data quality from the surveys and simply offer these findings to inform researchers in their choice of datasets that are fit for purpose, adjustments for measurement error, and so on. We do suggest, however, that while many differences between the CPS and ACS are statistically significant, the magnitude of the difference is fairly small in most cases. In our opinion, this evidence suggests that data users can take data quality off the table as a factor in their decisions about which survey to when making estimates of coverage type. For the uninsured measure the question is debatable given the 1.6 percentage point gap between surveys.

With regard to Medicaid in particular, there is a substantial literature linking survey reports to enrollment records, and Medicaid under-reporting in the pre-redesigned CPS has been thoroughly documented. Therefore, for Medicaid we can go beyond baseline findings and offer results in the context of the CPS pre- and post-redesign. One recent study (Noon et al. 2019) examined results from the pre-redesigned (aka traditional) CPS from 2000-2010. The under-reporting rate ranged from 38.8-44.7\%. In comparison, Table 2 shows the under-reporting rate for the redesigned CPS for public coverage to be $16.8 \%$. In terms of over-reporting, the Noon et al. study of the traditional CPS ranged from 20.7-26.8\%, while Table 2 shows over-reporting of public coverage to be $2.1 \%$. The Noon et al. study also provides results in terms of the "Medicaid undercount" - the difference between enrollment records and the survey estimate as a percent of the population prevalence - which ranged from $22-39 \%$ in the traditional CPS. To produce parallel metrics from findings in Table 2, we take the net prevalence difference of $4.3 \%$ points and divide it by the 28.4 prevalence in the records to get an undercount of $15.1 \%$. The same exercise in the Augmented sample yields a 17.8\% undercount. While there are many conditions in each study that hinder direct comparisons (e.g., in contrast to CHIME data, Noon et al. (2019) use CPS production data that were fully edited and imputed, and use a calendar year measure of insurance), results are consistent across all three metrics and provide compelling evidence that measurement error in the CPS has been reduced postredesign, perhaps by half or more. In other words, to the extent that the CHIME study conditions produce estimates that are comparable to the national CPS ASEC, there appear to be substantial improvements in Medicaid reporting accuracy in the CPS redesign.

In terms of next steps, we generally expect a survey with lower under- and over-reporting to produce a more accurate point estimate than a survey with higher levels of under- and overreporting. However, as was demonstrated above, in some cases the point estimate is closer to the population prevalence even if both under- and over-reporting are higher, due the two types of measurement error netting out. We explore the impact of this empirically by examining the 
demographic (e.g., age, household size, income) and health status characteristics of those reported to have a given coverage type in the survey and comparing that to the demographic profile of those with that coverage type according to the enrollment records for both survey treatments (Call et al. 2018). The trailing accuracy metrics for non-group/marketplace are also a subject for further investigation. Finally, future research will examine experimental questions embedded in the ACS about the marketplace, premiums and subsidies, which could be leveraged to separate public, non-group and marketplace coverage.

\section{Appendix}

\subsection{Appendix A, Comparison of Matched Individuals by Survey Treatment Arm}

Appendix A. Comparison of Matched Individuals by Survey Treatment Arm.

\begin{tabular}{|c|c|c|c|}
\hline & CPS & ACS & $\mathrm{p}$-value \\
\hline Female & $51 \%$ & $54 \%$ & 0.1284 \\
\hline $\begin{array}{l}\text { Respondent } \\
\text { Child of respondent } \\
\text { Spouse of respondent } \\
\text { Other person in household }\end{array}$ & $\begin{array}{r}52 \% \\
27 \% \\
17 \% \\
3 \%\end{array}$ & $\begin{array}{r}52 \% \\
27 \% \\
18 \% \\
3 \%\end{array}$ & 0.9311 \\
\hline $\begin{array}{l}\text { Resides in } 1 \text { person household } \\
\text { Resides in } 2-4 \text { person household } \\
\text { Resides in } 5+\text { person household } \\
\text { Family size unknown }\end{array}$ & $\begin{array}{r}25 \% \\
57 \% \\
18 \% \\
0 \%\end{array}$ & $\begin{array}{r}24 \% \\
43 \% \\
33 \% \\
0 \%\end{array}$ & 0.0270 \\
\hline $\begin{array}{l}\text { Non-Hispanic White } \\
\text { Non-Hispanic Black } \\
\text { Hispanic } \\
\text { Other race, non-Hispanic }\end{array}$ & $\begin{array}{r}83 \% \\
8 \% \\
4 \% \\
5 \%\end{array}$ & $\begin{array}{r}81 \% \\
7 \% \\
5 \% \\
7 \%\end{array}$ & 0.0072 \\
\hline $\begin{array}{l}\text { Family income }<138 \% \text { FPL } \\
\text { Family income } 139-199 \% \text { FPL } \\
\text { Family income } 200-400 \% \text { FPL } \\
\text { Family income }>400 \% \text { FPL } \\
\text { Family income unknown }\end{array}$ & $\begin{array}{r}23 \% \\
17 \% \\
32 \% \\
26 \% \\
2 \%\end{array}$ & $\begin{array}{r}23 \% \\
20 \% \\
29 \% \\
26 \% \\
2 \%\end{array}$ & 0.0547 \\
\hline $\begin{array}{l}\text { Full-year Full-time employed } \\
\text { Less than full-time employed } \\
\text { Out of the labor force } \\
\text { Under } 15 \\
\text { Employment status unknown }\end{array}$ & $\begin{array}{r}33 \% \\
29 \% \\
15 \% \\
21 \% \\
3 \%\end{array}$ & $\begin{array}{r}31 \% \\
30 \% \\
17 \% \\
20 \% \\
3 \%\end{array}$ & 0.3850 \\
\hline $\begin{array}{l}\text { Employer }<10 \text { employees } \\
\text { Employer } 10-50 \text { employees } \\
\text { Employer } 51-99 \text { employees } \\
\text { Employer } 100+\text { employees } \\
\text { Unknown employer size }\end{array}$ & $\begin{array}{r}35 \% \\
19 \% \\
6 \% \\
32 \% \\
7 \%\end{array}$ & $\begin{array}{r}35 \% \\
20 \% \\
5 \% \\
34 \% \\
6 \%\end{array}$ & 0.3884 \\
\hline $\begin{array}{l}\text { Less than high school } \\
\text { High school graduate } \\
\text { Some college or Associate's degree } \\
\text { Bachelor's degree or more } \\
\text { Education is unknown }\end{array}$ & $\begin{array}{r}8 \% \\
24 \% \\
31 \% \\
37 \% \\
0 \%\end{array}$ & $\begin{array}{r}8 \% \\
27 \% \\
30 \% \\
35 \% \\
0 \%\end{array}$ & 0.5234 \\
\hline $\begin{array}{l}\text { Married } \\
\text { Divorced/separated/widowed } \\
\text { Never married } \\
\text { Marital status is unknown }\end{array}$ & $\begin{array}{r}50 \% \\
15 \% \\
35 \% \\
0 \%\end{array}$ & $\begin{array}{r}50 \% \\
17 \% \\
33 \% \\
0 \%\end{array}$ & 0.1826 \\
\hline
\end{tabular}

Note: Chi-square tests were performed to test for differences across groups. 
7.2. Appendix B, CPS versus Unadjusted ACS Estimates

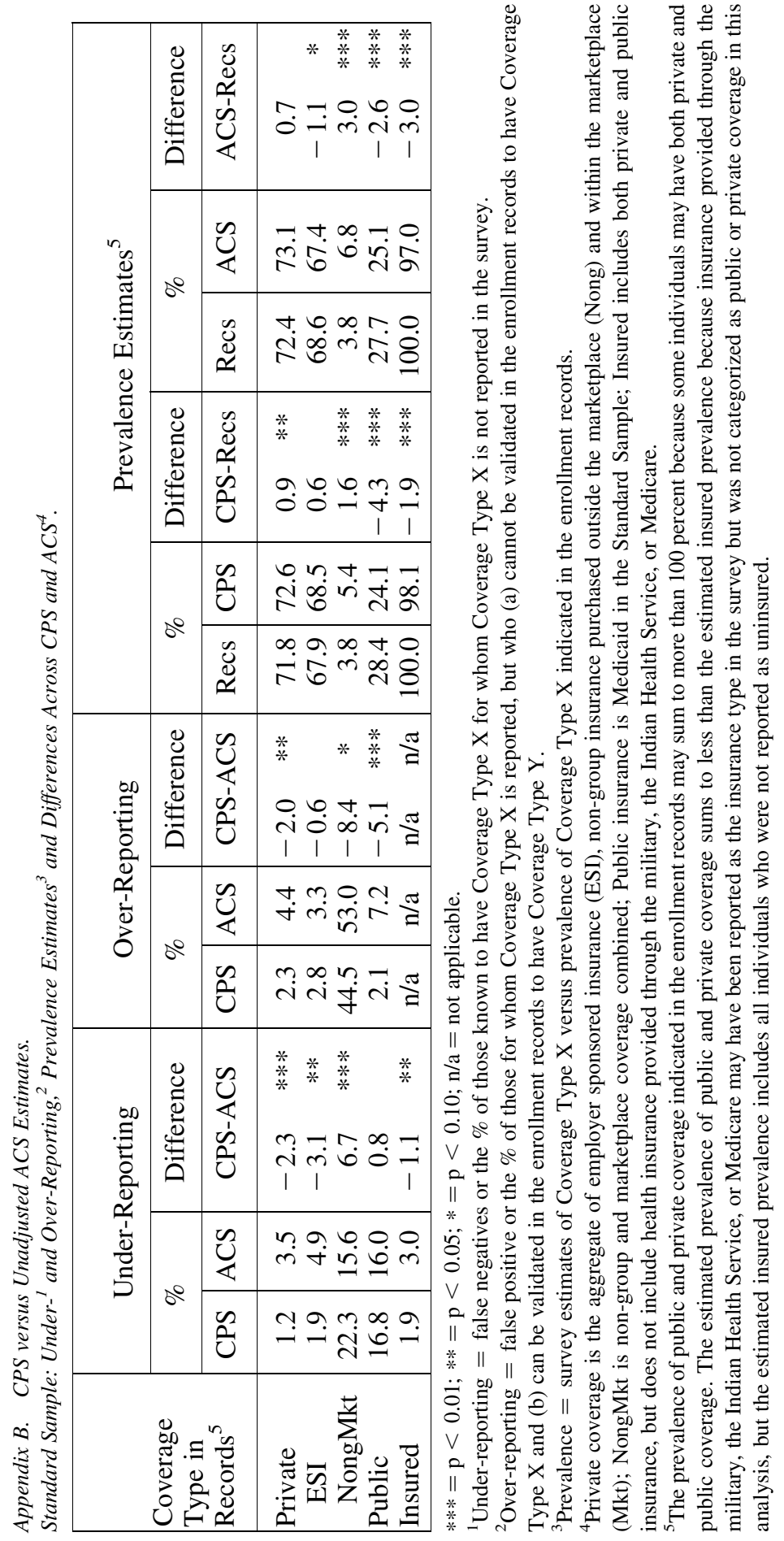




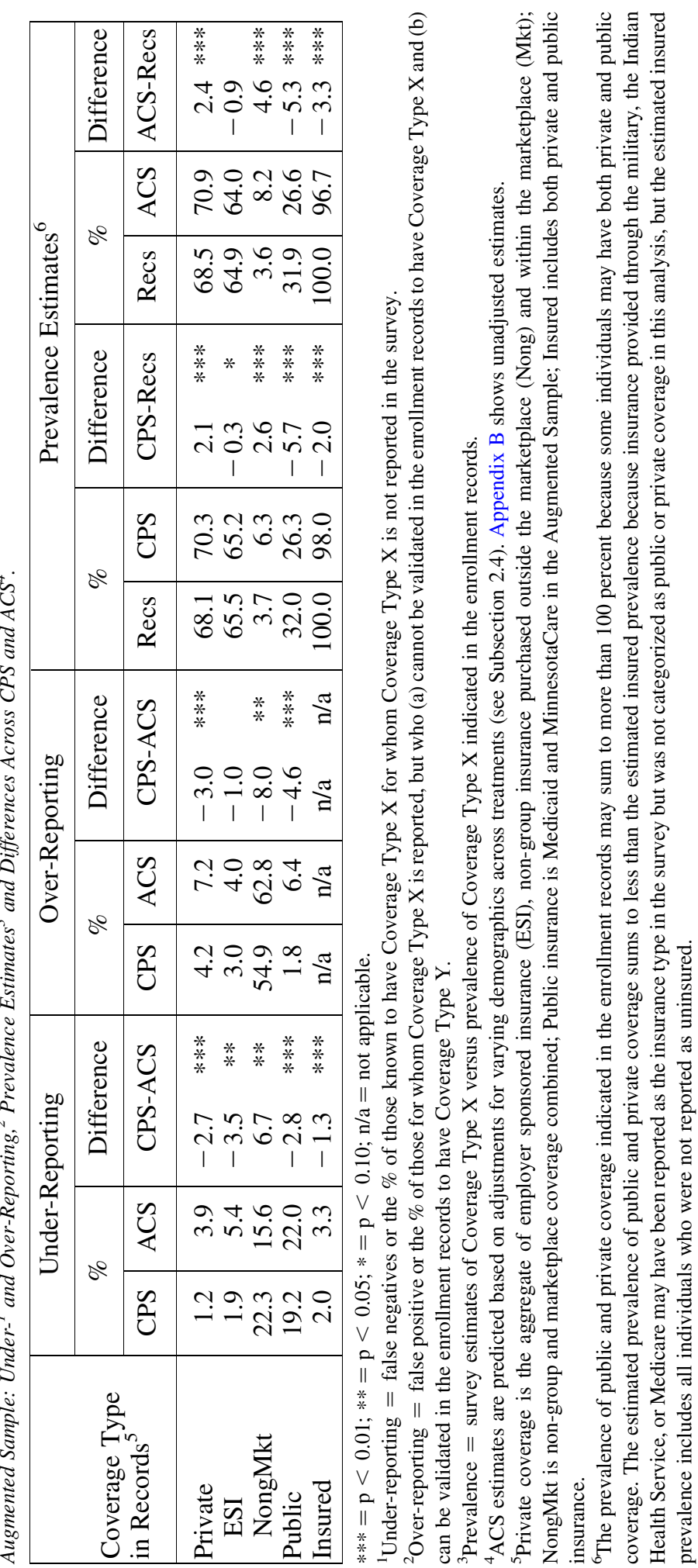


7.3. Appendix C, CPS AND ACS Survey Modules

\section{APPENDIX C. CPS AND ACS SURVEY MODULES}

\section{CPS Health Insurance Module}

\section{Section A: Coverage Status}

\section{HINTRO}

These next questions are about health coverage between January 1, [CY-1] and now.

- $\quad$ Press 1 to continue $\rightarrow$ PINTRO

\section{PINTRO}

[First/Next] I'm going to ask about [your/NAME's] health coverage.

- $\quad$ Press 1 to continue $\rightarrow$ CK-MCARE1

\section{CK-MCARE1}

Is NAME either $65+$ ?

- $\mathrm{Yes} \rightarrow \mathrm{MCARE} 1$

- $\mathrm{No} \rightarrow \mathrm{ANYCOV}$

\section{MCARE1}

Medicare is health insurance for people 65 years and older and people under 65 with disabilities. [Are you/Is NAME] NOW covered by Medicare?

- Code Medicare Parts A, B and C and Medicare Advantage as "Yes".

1. Yes $\rightarrow$ BEFORAFT_LC1

2. $\mathrm{No} / \mathrm{DK} / \mathrm{REF} \rightarrow \mathrm{ANYCOV}$
ANYCOV
[Do you/Does NAME] NOW have any type of health plan or health coverage?
1. Yes $\rightarrow$ SRCEGEN_LC1
2. $\mathrm{No} / \mathrm{DK} / \mathrm{REF} \rightarrow \mathrm{MEDI}$

\section{MEDI}

[Are you/Is NAME] NOW covered by Medicaid, Medical Assistance [or] CHIP [if MCARE1 not yet asked: or Medicare]?

1. Yes $\rightarrow$ GOVTYPE_LC1

2. $\mathrm{No} / \mathrm{DK} / \mathrm{REF} \rightarrow \mathrm{OTHGOVT}$

\section{OTHGOVT}

[Are you/Is NAME] NOW covered by a state or government assistance program that helps pay for healthcare, such as MinnesotaCare, Minnesota Comprehensive Health Association (MCHA), PMAP, MNsure or healthcare.gov?

[NOTE: Minnesota example is shown; question text fills all known state-specific program names for Medicaid and CHIP, all state-specific government program names, and all statespecific names for marketplace coverage] 
- Stop reading the list if respondent says "YES."

1. Yes $\rightarrow$ GOVPLAN_LC1

2. $\mathrm{No} / \mathrm{DK} / \mathrm{REF} \rightarrow$ If ever served in Armed Forces $($ AFEVER $=1) \rightarrow$ VET; else $\rightarrow$ VERIFY

\section{VET}

[Are you/Is NAME] NOW covered by Veteran's Administration (VA) care?

1. Yes $\rightarrow$ BEFORAFT_LC1

2. $\mathrm{No} / \mathrm{DK} / \mathrm{REF} \rightarrow \mathrm{VERIFY}$

\section{VERIFY}

I have recorded that [you are/NAME is] not currently covered by a health plan. Is that correct?

1. Yes, is NOT covered $\rightarrow$ ADDOTH1_L

2. No, is covered $\rightarrow$ SRCEGEN_LC1

3. DK/REF $\rightarrow$ ADDOTH1_L

\section{$\underline{\text { Section B: Plan Type }}$}

\section{SRCEGEN_LC1}

ASK OR VERIFY

For the coverage you/NAME has/have NOW, [do you/does NAME] get it through a job, the government or state, or some other way?

$\checkmark \quad$ JOB: Former job/Retiree, Union, Spouse/parent's job, Job with the government, COBRA, TRICARE/TRICARE for Life

$\checkmark$ GOVERNMENT OR STATE: Medical Assistance, Medicaid, Medicare (Parts A + B; Part C), Medicare Advantage, State-provided health coverage, VA Care/CHAMPVA/other military

- OTHER: Privately purchased, Parent or spouse, Medicare Supplements, Exchange plan/Marketplace, Group or association, School,

$\checkmark \quad$ IF RESPONDENT CHOOSES MORE THAN ONE: Ok let's talk about one plan at a time. Which would you like to tell me about first?

If VERIFY $=2$ then fill: $\bullet$ If respondent is not covered, go back to VERIFY and select "Yes"

1. Job (current or former) $\rightarrow$ MILPLAN_LC1

2. Government or State $\rightarrow$ JOBCOV_LC1

3. Other way $\rightarrow$ SRCEDEPDIR_LC1

- $\mathrm{DK} / \mathrm{REF} \rightarrow$ SRCEDEPDIR_LC1

\section{SRCEDEPDIR_LC1}

$\bullet \quad$ ASK OR VERIFY

[Do you/Does NAME] get that coverage through a parent or spouse, [do you/does he/she] buy it [yourself/himself/herself], or [do you/does he/she] get it some other way?

PARENT/SPOUSE: Parent, Spouse

BUY IT DIRECTLY: Buy it, Parent or spouse buys it, Medicare Supplement 
SOME OTHER WAY: Former employer, Group or association, Indian Health Service, School

1. Parent or spouse $\rightarrow$ POLHOLDER_LC1

2. Buy it $\rightarrow$ POLHOLDER_LC1

3. Other way $\rightarrow$ SRCEOTH_LC1

- $\mathrm{DK} / \mathrm{REF} \rightarrow$ SRCEOTH_LC1

\section{SRCEOTH_LC1}

\section{ASK OR VERIFY}

[Do you/Does NAME] get it through a former employer, a union, a group or association, the Indian Health Service, a school, or some other way?

1. Former employer $\rightarrow$ POLHOLDER_LC1

2. Union $\rightarrow$ POLHOLDER_LC1

3. Group or association $\rightarrow$ POLHOLDER_LC1

4. Indian Health Service $\rightarrow$ BEFORAFT_LC1

5. School $\rightarrow$ POLHOLDER_LC1

6. Some other way $\rightarrow$ GOVPLAN_LC1

- $\overline{\mathrm{DK}} / \mathrm{REF} \rightarrow \mathrm{GOVPLAN} \_L C 1$

\section{JOBCOV_LC1}

Is that coverage related to a JOB with the government or state?

$\checkmark \quad$ Include coverage through FORMER employers and unions, and COBRA plans.

1. Yes $\rightarrow$ MILPLAN_LC1

2. No $\rightarrow$ GOVTYPE_LC1

- $\mathrm{DK} / \mathrm{REF} \rightarrow$ GOVTYPE_LC1

Soft edit: If "yes" and no one in the household was reported to have a job (more than part time, seasonal or temp work), nor is anyone in the household a retiree, then ask soft edit: "Can I just check - I recorded that this coverage is related to a JOB. Is that correct?"

$\checkmark$ If this is correct, continue to MILPLAN_LC1

$\checkmark$ If this is not correct, go back to JOBCOV_LC1 and correct

\section{MILPLAN_LC1}

- ASK OR VERIFY

Is that plan related to military service in any way?

- Examples of military plans include:

- VA Care

- TRICARE

- TRICARE for Life

- CHAMPVA

- Other military care

1. Yes $\rightarrow$ MILTYPE_LC1

2. No $\rightarrow$ POLHOLDER_LC1

- $\mathrm{DK} / \mathrm{REF} \rightarrow$ POLHOLDER_LC1 


\section{GOVTYPE_LC1}

\section{$\checkmark \quad$ ASK OR VERIFY}

Is that coverage Medicaid, CHIP, Medicare, a plan through the military, or some other program?

$\checkmark \quad$ Code Medicare Parts A, B and C and Medicare Advantage as "Medicare".

IF R CHOOSES MORE THAN ONE: Ok let's talk about one plan at a time. Which would you like to tell me about first?

1. Medicaid or Medical Assistance $\rightarrow$ GOVPLAN_LC1

2. $\mathrm{CHIP} \rightarrow$ PORTAL_LC1

3. Medicare $\rightarrow$ soft edit then $\rightarrow$ BEFORAFT_LC1

4. Military $\rightarrow$ MILTYPE_LC1

5. Other $\rightarrow$ GOVPLAN_LC1

- $\quad \mathrm{DK} / \mathrm{REF} \rightarrow$ GOVPLAN_LC1

Soft edit: if Medicare is selected and NAME is under 65 ask: "There are two programs that sound a lot alike. MediCARE is for people 65 years and older, or people under 65 with disabilities. MediCAID is a government-assistance plan for those with low-incomes or a disability. Just to be sure, which program are you/is NAME covered by?"

$\checkmark$ If Medicare is correct, suppress and continue.

- If Medicare is not correct, go back to GOVTYPE_LC1 and correct.

\section{MILTYPE_LC1}

\section{$\checkmark \quad$ ASK OR VERIFY}

Is that plan through TRICARE, TRICARE for Life, CHAMPVA, VA care, military health care, or something else?

1. TRICARE

2. TRICARE for Life

3. CHAMPVA

4. Veterans Administration (VA) care

5. Military health care

6. Other

- DK/REF

[all $\rightarrow$ POLHOLDER_LC1

\section{POLHOLDER_LC1}

\section{$\checkmark \quad$ ASK OR VERIFY}

Whose name is the policy in? (Who is the policyholder)?

1. household member 1

2. household member 2

16. household member 16

17. Someone living outside the household

- DK/REF

[all] $\rightarrow$ CK-SRCEPTSP_LC1 


\section{CK-SRCEPTSP_LC1}

- If SRCEDEPDIR_LC1 = "parent or spouse" then $\rightarrow$ SRCEPTSP_LC1

- Else if SRCEDEPDIR_LC1 = 2 = "buy it" then $\rightarrow$ PORTAL_LC1

- $\quad$ Else $\rightarrow$ CK-HIPAID_LC1

\section{SRCEPTSP_LC1}

\section{ASK OR VERIFY}

Do they get that coverage through their job, do they buy it themselves, or do they get it some other way?

1. Job (current or former) $\rightarrow$ HIPAID_LC1

2. Buy it $\rightarrow$ PORTAL_LC1

3. Other way $\rightarrow$ GOVPLAN_LC1

- $\mathrm{DK} / \mathrm{REF} \rightarrow$ GOVPLAN_LC1

\section{GOVPLAN_LC1}

ASK OR VERIFY

What do you call the program?

IF RESPONDENT ANSWERS WITH INSURANCE COMPANY NAME: OK, so that would be the plan name. What do you call the program? Some examples of programs in [STATE] are [read full list below].

NOTE: Some response categories are generic (regardless of state) and some are statespecific. The generic response categories are: 1, 2, 3, 13, 17 and 18. Response categories 4-12 fill up to nine state-specific names for Medicaid, CHIP and other state-sponsored government programs. If there are fewer than nine, only response categories with a program name are displayed. Response categories 14-16 display the state-specific names for the Marketplace and only response categories with Marketplace names are displayed.

1. Medicaid

2. Medical Assistance

3. Indian Health Service

4. MinnesotaCare

5. Minnesota Comprehensive Health Association (MCHA)

6. PMAP

13. Healthcare.gov

16. Plan through MNsure

17. Other government plan

18. Other (please specify)

- DK/REF

Skip Instructions

- if 3 (IHS) $\rightarrow$ BEFORAFT_LC1

- else if 17, 18 (non-specific other government plan or other/specify) then $\rightarrow$ MISCSPEC_LC1

- else if 13-16 (marketplace plan) then $\rightarrow$ POLHOLDER2_LC1

- all others (Medicaid, CHIP, state-specific government plan, DK, REF) $\rightarrow$ PORTAL_LC1 


\section{MISCSPEC_LC1}

[open text; 65 characters] $\rightarrow$ PORTAL_LC1

\section{PORTAL_LC1}

\section{$\checkmark \quad$ ASK OR VERIFY}

Is that coverage through MNsure, which may also be known as healthcare.gov?

1. Yes $\rightarrow$ EXCHTYPE_LC1

2. No $\rightarrow$ CK-POLHOLDER2_LC1

- $\mathrm{DK} / \mathrm{REF} \rightarrow \mathrm{CK}-\mathrm{POLHOLDER} 2 \_L C 1$

\section{EXCHTYPE_LC1}

\section{ASK OR VERIFY}

What do you call it - MNsure or healthcare.gov?

1. MNsure

2. Healthcare.gov

- DK/REF

[all] $\rightarrow$ CK-POLHOLDER2_LC1

\section{CK-HIPAID_LC1}

Is coverage related to employment?

- $\quad$ Yes $\rightarrow$ HIPAID_LC1

- $\quad$ No $\rightarrow$ BEFOREAFT_LC1

\section{HIPAID_LC1}

Does (name's/policyholder names's) employer or union pay for all, part, or none of the health insurance premium?

Report here employer's contribution to employee's health insurance premiums, not the employee's medical bills.

1. All

2. Part

3. None

- DK/REF

[all] $\rightarrow$ BEFOREAFT_LC1

\section{CK-POLHOLDER2_LC1}

Was POLHOLDER_LC1 already asked?

- $\quad$ Yes $\rightarrow$ PREMYN_LC1

- $\quad$ No $\rightarrow$ POLHOLDER2_LC1

\section{POLHOLDER2_LC1}

\section{$\checkmark \quad$ ASK OR VERIFY}

Whose name is the policy in (Who is the policyholder)?

1. household member 1

2. household member 2 
16. household member 16

17. Someone living outside the household

- $\mathrm{DK} / \mathrm{REF}$

[all] $\rightarrow$ PREMYN_LC1

\section{PREMYN_LC1}

Is there a monthly premium for this plan?

- READ IF NECESSARY: A monthly premium is a fixed amount of money people pay each month to have health coverage. It does not include copays or other expenses such as prescription costs.

1. Yes $\rightarrow$ PREMSUBS_LC1

2. No $\rightarrow$ METAL_LC1

- $\mathrm{DK} / \mathrm{REF} \rightarrow \mathrm{METAL} \_\mathrm{LC} 1$

\section{PREMSUBS_LC1}

Is the cost of the premium subsidized based on [if single-person hh and NAME is policyholder fill: your/else fill: family] income?

$\checkmark \quad$ READ IF NECESSARY: A monthly premium is a fixed amount of money people pay each month to have health coverage. It does not include copays or other expenses such as prescription costs.

$\checkmark \quad$ READ IF NECESSARY: Subsidized health coverage is insurance with a reduced premium. Low and middle income families are eligible to receive tax credits that allow them to pay lower premiums for insurance bought through healthcare exchanges or marketplaces.

1. Yes

2. No

- $\mathrm{DK} / \mathrm{REF}$

[all] $\rightarrow$ PREMCOST_LC1

\section{PREMCOST_LC1}

How much is the premium for this plan?

READ IF NECESSARY: A monthly premium is a fixed amount of money people pay each month to have health coverage. It does not include copays, deductibles, or other expenses such as prescription costs.

[open text] $\rightarrow$ PREMUNIT_LC1

- $\mathrm{DK} / \mathrm{REF} \rightarrow \mathrm{METAL} \_$LC1

\section{PREMUNIT_LC1}

ASK OR VERIFY

Is that per month, quarter, year, or some other time period?

1. Every 2 weeks

2. Month

3. Quarter

4. Year

5. Other (please specify) $\rightarrow$ UNITSP_LC1 (open-text specify) 
- DK/Ref

$\Rightarrow$ METAL_LC1

\section{METAL_LC1}

Some health plans are sold at different levels of coverage: bronze, silver, gold and platinum. And some people, including young people under 30, can purchase a catastrophic plan. Is this plan a. . .

[READ LIST; ENTER ONLY ONE].

NOTE: Catastrophic plans are only available for those under 30 years old or those with a "hardship exemption"

1. Bronze

2. Silver

3. Gold

4. Platinum or a

5. Catastrophic plan or

6. None of the above?

- DK/Ref

$\Rightarrow$ BEFORAFT_LC1

\section{Section C: Months of Coverage}

\section{BEFORAFT_LC1}

Did [your/NAME's] coverage from [PLANTYPE] start before January 1, [CY-1]?

$\checkmark \quad$ READ IF NECESSARY: Your best estimate is fine.

If PLANTYPE is job-related fill:

- READ IF NECESSARY: If [you/POLICYHOLDER NAME] switched employers or plans through [your/their] employer, consider it the same plan.

If PLANTYPE is directly-purchased fill:

$\checkmark \quad$ READ IF NECESSARY: If [you/POLICYHOLDER NAME] switched plans that you/he/she buys, consider it the same plan.

1. Yes $\rightarrow$ CNTCOV_LC1

2. No $\rightarrow$ MNTHBEG1_LC1

- $\quad \mathrm{DK} / \mathrm{REF} \rightarrow$ ANYTHIS_LC1

\section{MNTHBEG1_LC1}

In which month did that coverage start?

READ IF NECESSARY: Your best estimate is fine.

If PLANTYPE is job-related fill:

- READ IF NECESSARY: If [you/POLICYHOLDER NAME] switched employers or plans through [your/their] employer, consider it the same plan.

If PLANTYPE is directly-purchased fill:

$\checkmark \quad$ READ IF NECESSARY: If [you/POLICYHOLDER NAME] switched plans that you/he/she buys, consider it the same plan.

$\checkmark \quad$ This question refers to [PLANTYPE]. 
1. January

2. February

12. December

- DK/REF

If MNTHBEG1_LC1 = current month or earlier $\rightarrow$ YEARBEG1_LC1

If MNTHBEG1_LC1 $=$ later than current month $\rightarrow$ CNTCOV_LC1

If MNTHBEG1_LC1 $=(\mathrm{D} / \mathrm{R}) \rightarrow$ ANYTHIS_LC1

\section{YEARBEG1_LC1}

\section{$\checkmark \quad$ ASK OR VERIFY}

Which year was that?

If PLANTYPE is job-related fill:

- READ IF NECESSARY: If [you/POLICYHOLDER NAME] switched employers or plans through [your/their] employer, consider it the same plan.

If PLANTYPE is directly-purchased fill:

$\checkmark \quad$ READ IF NECESSARY: If [you/POLICYHOLDER NAME] switched plans that you/he/she buys, consider it the same plan.

- This question refers to [PLANTYPE].

1. $\mathrm{CY}-1 \rightarrow$ CNTCOV_LC1

2. $\mathrm{CY} \rightarrow \mathrm{CNTCOV} \_\mathrm{LC} 1$

- $\quad \mathrm{DK} / \mathrm{REF} \rightarrow$ ANYTHIS_LC1

\section{CNTCOV_LC1}

Has it been continuous since [January, CY-1/month and year from MNTH/YRBEG1]? If PLANTYPE is job-related fill:

$\checkmark \quad$ READ IF NECESSARY: If [you/POLICYHOLDER NAME] switched employers or plans through [your/their] employer, consider it the same plan.

If PLANTYPE is directly-purchased fill:

$\checkmark \quad$ READ IF NECESSARY: If [you/POLICYHOLDER NAME] switched plans that you/he/she buys, consider it the same plan.

- READ IF NECESSARY: If the gap in coverage was less than three weeks, consider the coverage "continuous."

- This question refers to [PLANTYPE].

1. Yes $\rightarrow$ CK-OTHMEMB_LC1

2. No $\rightarrow$ MNTHBEG2_LC1

- $\mathrm{DK} \rightarrow$ MNTHBEG2_LC1

- $\mathrm{REF} \rightarrow$ ANYTHIS_LC1

\section{MNTHBEG2_LC1}

In which month did this most recent period of coverage start?

$\checkmark \quad$ READ IF NECESSARY: Your best estimate is fine.

If PLANTYPE is job-related fill:

- READ IF NECESSARY: If [you/POLICYHOLDER NAME] switched employers or plans through [your/their] employer, consider it the same plan. 
If PLANTYPE is directly-purchased fill:

READ IF NECESSARY: If [you/POLICYHOLDER NAME] switched plans that you/he/she buys, consider it the same plan.

- This question refers to [PLANTYPE].

1. January

2. February

12. December

- $\mathrm{DK} / \mathrm{REF}$

If MNTHBEG2_LC1 $=$ current month or earlier $\rightarrow$ YEARBEG2_LC1

If MNTHBEG2_LC1 $=$ later than current month $\rightarrow$ SPELLADD_LC1

Else If MNTHBEG2_LC1 $=(\mathrm{D} / \mathrm{R}) \rightarrow$ if covered all months of $\mathrm{CY}=>$ ANYLAST_LC1; else $\rightarrow$ ANYTHIS_LC1

\section{YEARBEG2_LC1}

\section{$\checkmark \quad$ ASK OR VERIFY}

Which year was that?

If PLANTYPE is job-related fill:

$\checkmark \quad$ READ IF NECESSARY: If [you/POLICYHOLDER NAME] switched employers or plans through [your/their] employer, consider it the same plan.

If PLANTYPE is directly-purchased fill:

$\checkmark \quad$ READ IF NECESSARY: If [you/POLICYHOLDER NAME] switched plans that you/he/she buys, consider it the same plan.

$\checkmark \quad$ This question refers to [PLANTYPE].

1. $[\mathrm{CY}-1] \rightarrow$ SPELLADD_LC1

2. $[\mathrm{CY}] \rightarrow$ SPELLADD_LC1

- $\quad \mathrm{DK} \rightarrow$ if covered all months of $\mathrm{CY} \rightarrow$ ANYLAST_LC1; else $\rightarrow$ ANYTHIS_LC1

- $\quad \mathrm{REF} \rightarrow$ if covered all months of $\mathrm{CY} \rightarrow$ ANYLAST_LC1; else $\rightarrow$ ANYTHIS_LC1

\section{SPELLADD_LC1}

I have recorded that [you were/NAME was] covered by [PLANTYPE] in [read months covered]. Were there any OTHER months between January [CY-1] and now that [you were/NAME was] also covered by [PLANTYPE]?

1. Yes $\rightarrow$ if covered all months of $\mathrm{CY} \rightarrow$ ANYLAST_LC1; else $\rightarrow$ ANYTHIS_LC1

2. No $\rightarrow$ CK-OTHMEMB_LC1

- $\quad \mathrm{DK} / \mathrm{REF} \rightarrow \mathrm{CK}-\mathrm{OTHMEMB} \_\mathrm{LC} 1$

\section{ANYTHIS_LC1}

Which months [were you/was NAME] covered by [PLANTYPE] THIS year - in [CY]?

- Choose all months that apply

1. January

2. February

3. March

4. April

20. All months of CY 
21. No months of CY

- DK/REF

[all] $\rightarrow$ ANYLAST_LC1

\section{ANYLAST_LC1}

Which months [were you/was NAME] covered by [PLANTYPE] LAST year - in [CY-1]?

- Choose all months that apply

1. January

2. February

12. December

20. All months of CY-1

21. No months of CY-1

- $\mathrm{DK} / \mathrm{REF}$

[all] $\rightarrow$ CK-OTHMEMB_LC1

\section{CK-OTHMEMB_LC1}

Does this household have 2 or more members?

- $\quad$ Yes $\rightarrow$ OTHMEMB_LC1

- $\quad \mathrm{No} \rightarrow$ CK-OTHOUT_LC1

Section D: Other Household Members Covered by Leader's Plan, and Months Covered

\section{OTHMEMB_LC1}

Between January 1, [CY-1] and now, was anyone in the household other than [you/NAME] ALSO covered by [PLANTYPE]?

1. Yes $\rightarrow$ COVWHO_LC1

2. No $\rightarrow$ CK-OTHOUT_LC1

- $\quad \mathrm{DK} / \mathrm{REF} \rightarrow \mathrm{CK}-\mathrm{OTHOUT}$ LCC1

Hard edit: If NAME is a dependent on a job or direct-purchase plan and OTHMEMB_LC1 ne "yes" (that is, the respondent fails to report that the policyholder is also on the plan) store a "Yes"

\section{COVWHO_LC1}

Who else was covered? (Who else was covered by [PLANTYPE]?)

PROBE: Anyone else?

0 . household member 1

1. household member 2

16. household member 16

96. all persons listed

97. DK/REF

- Any household member $\rightarrow$ CK-SAMEMNTHS_LC1

- $\quad$ DK/REF $=>$ CK-OTHOUT_LC1

Hard edit: If NAME is a dependent on a job or direct-purchase plan and the policyholder is not selected, store policyholder's name in COVWHO_LC1 


\section{CK-SAMEMNTHS_LC1}

- If leader was covered all months $\rightarrow$ SAMEMNTHS_LC1

- If leader was NOT covered all months $\rightarrow$ MNTHS_LC1

\section{SAMEMNTHS_LC1}

[Was/Were] [NAME/NAMEs] also covered from January 1, CY-1 until now?

- This question refers to [PLANTYPE].

1. Yes (all also covered from January CY-1 until now) $\rightarrow$ CK-OTHOUT_LC1

2. No (at least one person not covered from January, CY-1 until now)

- $\quad \mathrm{DK} / \mathrm{REF} \rightarrow \mathrm{MNTHS} \_$LC1

\section{MNTHS_LC1}

[First person] Which months between January [CY-1] and now was [NAME from COVWHO_LC1] covered?

[Second + person] How about NAME? (Which months between January [CY-1] and now was [NAME] covered?)

- Choose all months that apply

- This question refers to [PLANTYPE].

1. January CY-1

2. February $\mathrm{CY}-1$

12. December CY-1

13. January CY

14. February CY

15. March CY

16. April CY

17. $\mathrm{DK} / \mathrm{REF}$

20. All months from January 2013 until now

21. No months from January 2013 until now

[all] $\rightarrow$ Loop through all persons reported in COVWHO_LC1; then $=>$ CKOTHOUT_LC1

\section{CK-OTHOUT_LC1}

- If PLANTYPE is private $\rightarrow$ OTHOUT_LC1

- $\quad$ Else $\rightarrow$ CK-ADDGAP1_L

\section{OTHOUT_LC1}

Does that plan cover anyone living outside this household?

1. Yes $\rightarrow$ OTHWHO_LC1

2. No $\rightarrow$ CK- ADDGAP1_L

- $\mathrm{DK} / \mathrm{REF} \rightarrow \mathrm{CK}-\mathrm{ADDGAP} 1 \_\mathrm{L}$

\section{OTHWHO_LC1}

How old are they - under 19, 19-25 or older than 25? [MARK ALL THAT APPLY]?

1. Under 19

2. 19-25 years old 
3. Older than 25

- DK/REF

[all] $\rightarrow$ CK-ADDGAP1_L

\section{Additional Plans}

\section{$\overline{\text { CK-ADDGAP1_L }}$}

Are there any gaps in coverage for NAME?

- Yes (gaps in coverage) $\rightarrow$ ADDGAP1_L

- $\quad$ No (no gaps in coverage) $\rightarrow$ ADDOTH1_L

\section{ADDGAP1_L}

So far, I have recorded that [you were/NAME was] NOT covered in [months not covered]. [Were you/Was NAME] covered by any type of health plan or health coverage in [that/those] month(s)?

$\checkmark$ READ IF NECESSARY: Do not include plans that cover only one type of care, such as dental or vision plans.

1. Yes $\rightarrow$ SRCEGEN_LP1

2. No $\rightarrow$ ADDOTH1_L

- $\mathrm{DK} / \mathrm{REF} \rightarrow$ ADDOTH1_L

\section{Past Loop}

The Past Loop is designed to capture plan type, months of coverage, other household members covered by the same plan, and the months they were covered. As such, the Past Loop consists of all items in Sections B through D above, but with the following exceptions. First, all items in the Past Loop are worded in the past tense. Second, for Section $\mathrm{C}$ of the past loop, there is only a single item asking about months of coverage. This is because for current coverage the questionnaire anchors the respondent in their dayof coverage and then establishes the start month of the spell. For coverage that is not held on the day of the interview it is not possible to employ this same technique so we simply ask what months throughout the 16-month reference period the coverage was held, as follows:

\section{WMNTHS_LP1}

Which months between January [CY-1] and now [were you/was NAME] covered by [PLANTYPE]?

- Choose all months that apply

1. January CY-1

2. February $\mathrm{CY}-1$

12. December CY-1

13. January CY

14. February CY

15. March CY

16. April CY

17. DK/REF 
20. All months from January 2013 until now

21. No months from January 2013 until now

[all] $\rightarrow$ CK-OTHMEMB_LP1

Once months of coverage are established for the leader, the respondent skips to Section D to determine whether other household members were also covered by the same plan.

\section{SRCEGEN_LP1 thru OTHWHO_LP1}

- Copy all items in Sections B through D in the Current Loop (with the exception above for Section C) and replace "_LC1” with “_LP1.”

- All answer choices at end of Section D => ADDOTH1_L

\section{ADDOTH1_L}

[Other than [PLANTYPEs],] [W/were you/W/was NAME] covered by any [other] health plan or health coverage AT ANY TIME between January 1, CY-1 and now?

READ IF NECESSARY: Do not include plans that cover only one type of care, such as dental or vision plans.

1. Yes $\rightarrow$ SRCEGEN_LP2

2. $\mathrm{No} \rightarrow$ CK-NEXTMEMB

- $\mathrm{DK} / \mathrm{REF} \rightarrow \mathrm{CK}-\mathrm{NEXTMEMB}$

If ADDOTH1_L is answered for Person 1 then set MARKTWO $=2$ (sufficient partial)

\section{SRCEGEN_LP2 thru OTHWHO_LP2}

- Copy all items in Past Loop and replace “_LP1” with “_LP2.”

- All answer choices at end of Section D => ADDOTH2_L

\section{ADDOTH2_L}

[Other than [PLANTYPEs],] [W/were you/W/was NAME] covered by any [other] health plan or health coverage AT ANY TIME between January 1, CY-1 and now?

$\checkmark$ READ IF NECESSARY: Do not include plans that cover only one type of care, such as dental or vision plans.

1. Yes $\rightarrow$ SRCEGEN_LP3

2. $\mathrm{No} \rightarrow$ CK-NEXTMEMB

- $\mathrm{DK} / \mathrm{REF} \rightarrow \mathrm{CK}-\mathrm{NEXTMEMB}$

\section{SRCEGEN_LP3 thru OTHWHO_LP3}

- copy all items in Past Loop and replace “_LP1” with “_LP3.”

- All answer choices at end of Section D $=>C K$-NEXTMEMB

\section{CK-NEXTMEMB}

Have all household members been asked about explicitly?

- Yes $\rightarrow$ HEALTHSTATUS_INTRO

- $\mathrm{No} \rightarrow$ FINTRO 


\section{Additional Plans for Follower}

\section{FHINTRO}

Next I'm going to ask you about NAME's health coverage.

$\diamond$ Press 1 to Continue

\section{CK-ADDGAP1_F}

Are there any gaps in coverage for NAME?

- Yes (gaps in coverage) $\rightarrow$ ADDGAP1_F

- $\quad$ No (no gaps in coverage) $\rightarrow$ ADDOTH1_F

\section{ADDGAP1_F}

So far, I have recorded that [you were/NAME was] NOT covered in [months not covered]. [Were you/Was NAME] covered by any type of health plan or health coverage in [that/those] month(s)?

- READ IF NECESSARY: Do not include plans that cover only one type of care, such as dental or vision plans.

1. Yes $\rightarrow$ SRCEGEN_FP1

2. No $\rightarrow$ ADDOTH1_F

- $\mathrm{DK} / \mathrm{REF} \rightarrow$ ADDOTH1_F

\section{SRCEGEN_FP1 thru OTHWHO_FP1}

- copy all items in Past Loop and replace “_LP1” with “_FP1.”

- All answer choices at end of Section D => ADDOTH1_F

\section{ADDOTH1_F}

[Other than [PLANTYPEs],] [W/were you/W/was NAME] covered by any [other] health plan or health coverage AT ANY TIME between January 1, CY-1 and now?

$\checkmark \quad$ READ IF NECESSARY: Do not include plans that cover only one type of care, such as dental or vision plans.

1. Yes $\rightarrow$ SRCEGEN_FP2

2. No $\rightarrow$ CK-NEXTMEMB2

- $\mathrm{DK} / \mathrm{REF} \rightarrow \mathrm{CK}-\mathrm{NEXTMEMB} 2$

\section{SRCEGEN_FP2 thru OTHWHO_FP2}

- copy all items in Past Loop and replace “_LP1” with “_FP2.”

- All answer choices at end of Section D =>ADDOTH2_F

\section{ADDOTH2_F}

[Other than [PLANTYPEs],] [W/were you/W/was NAME] covered by any [other] health plan or health coverage AT ANY TIME between January 1, CY-1 and now?

$\checkmark \quad$ READ IF NECESSARY: Do not include plans that cover only one type of care, such as dental or vision plans.

1. Yes $\rightarrow$ SRCEGEN_FP3

2. No $\rightarrow$ CK-NEXTMEMB2

- $\mathrm{DK} / \mathrm{REF} \rightarrow \mathrm{CK}-\mathrm{NEXTMEMB} 2$ 


\section{SRCEGEN_FP3 thru OTHWHO_FP3}

- copy all items in Past Loop and replace “_LP1” with “_FP3.”

- All answer choices at end of Section D => HEALTHSTATUS_INTRO

\section{CK-NEXTMEMB2}

Have all household members been asked about explicitly?

- $\quad$ Yes $\rightarrow$ HEALTHSTATUS_INTRO

- $\quad$ No $\rightarrow$ FINTRO for next person

\section{ACS Health Insurance Module}

\section{ACSJOB}

I am now going to ask you some questions about [your/NAME's] health insurance and health coverage. [Are you/Is NAME] currently covered by health insurance through a current or former employer or union of [yours/yours or another family member/ $<$ him/her $>$ or another family member]?

- NOTE: If the respondent says this person has health coverage through the military, mark " 2 " and tell them that military health insurance/coverage will be discussed later.

1. Yes

2. No

- $\mathrm{DK} / \mathrm{Ref}$

$\Rightarrow$ ACSDIR

\section{ACSDIR}

[Are you/Is NAME] currently covered by health insurance purchased directly from an insurance company by [you/you or another family member/ $<$ him/her $>$ or another family member]?

1. Yes

2. No

- DK/Ref

$\Rightarrow$ ACSMCARE

Soft Edit: if ACSJOB $=1$ and ACSDIR $=1$ ask: "I recorded that (Fill 1: you/ $<$ NAME $>$ ) (have/has) both insurance through an employer or union AND insurance directly purchased through an insurance company. These are two different plans, is that correct?"

$\checkmark$ If correct, suppress and continue.

$\checkmark$ If not, determine which is the primary plan and go back to and change the "yes" to a "no" for the other plan

\section{ACSMCARE}

[Are you/Is NAME] currently covered by Medicare, for people age 65 or older or people with certain disabilities?

1. Yes

2. No 
- $\mathrm{DK} / \mathrm{Ref}$

$\Rightarrow$ ACSMCAID

\section{ACSMCAID}

[Are you/Is NAME] currently covered by Medicaid, Medical Assistance, or any kind of government-assistance plan for those with low incomes or a disability?

1. Yes

2. No

- $\mathrm{DK} / \mathrm{Ref}$

$\Rightarrow$ ACSMIL

\section{ACSMIL}

[Are you/Is NAME] currently covered by TRICARE or other military health care?

1. Yes

2. No

- DK/Ref

$\Rightarrow$ ACSVA

\section{ACSVA}

[Are you/Is NAME] currently covered through the Veteran's Administration or [have you/has NAME] ever used or enrolled for VA health care)?

1. Yes

2. No

- $\mathrm{DK} / \mathrm{Ref}$

$$
\Rightarrow \text { ACSIHS }
$$

\section{ACSIHS}

[Are you/Is NAME] currently covered through the Indian Health Service?

1. Yes

2. No

- DK/Ref

$$
\Rightarrow \text { ACSOTHER }
$$

\section{ACSOTHER}

[Are you/Is NAME] currently covered by any other health insurance or health coverage plan?

1. Yes $\rightarrow$ ACSOTHERS

2. No $\rightarrow$ CK-ACSLAST

- $\mathrm{DK} / \mathrm{Ref} \rightarrow \mathrm{CK}-\mathrm{ACSLAST}$

\section{ACSOTHERS}

What is the name of the health care plan?

[open text; allow 30 characters]

$$
\Rightarrow \text { CK-ACSLAST }
$$




\section{CK-ACSLAST}

- If there is another person on the roster (regardless of age) $\rightarrow$ ACSJOB

- Else if at least one plan was reported $\rightarrow$ ACS_MKT

- $\quad$ Else $\rightarrow$ HEALTHSTAT

\section{ACS_MKT}

Was this plan obtained through a State or Federal Marketplace, Healthcare.gov, or a similar state website?

1. Yes

2. No

- $\mathrm{DK} / \mathrm{REF}$

$$
\Rightarrow \text { ACS_PREM }
$$

\section{ACS_PREM}

Do you or another family member pay a premium for this health insurance plan? A premium is a fixed amount of money paid on a regular basis for health coverage. It does not include copays, deductibles, or other expenses such as prescription costs.

1. Yes $\rightarrow$ ACS_SUBS

2. No $\rightarrow$ ACS_METAL

- $\quad$ DK/REF $\rightarrow$ ACS_METAL

\section{ACS_SUBS}

Based on family income, do you or another family member receive financial assistance through a subsidy or tax credit to help pay part or all of the cost of the premium for this plan?

1. Yes

2. No

- $\mathrm{DK} / \mathrm{REF}$

$$
\Rightarrow \text { ACS_PREMCOST }
$$

\section{ACS_PREMCOST}

How much is the premium for this plan?

READ IF NECESSARY: A premium is a fixed amount of money paid on a regular basis for health coverage. It does not include copays, deductibles, or other expenses such as prescription costs. [open text] $\rightarrow$ ACS_PREMUNIT

- $\quad \mathrm{DK} / \mathrm{REF} \rightarrow$ ACS_METAL

\section{ACS_PREMUNIT}

\section{ASK OR VERIFY}

Is that per month, quarter, year, or some other time period?

1. Every 2 weeks

2. Month

3. Quarter

4. Year 
5. Other (please specify) $\rightarrow$ ACS_UNITSP (open text specify)

- DK/Ref $\Rightarrow$ ACS_METAL

\section{ACS_METAL}

Some health plans are sold at different levels of coverage: bronze, silver, gold and platinum. And some people, including young people under 30, can purchase a catastrophic plan. Is this plan a. . .

[READ LIST; ENTER ONLY ONE].

NOTE: Catastrophic plans are only available for those under 30 years old or those with a "hardship exemption"
1. Bronze
2. Silver
3. Gold
4. Platinum or a
5. Catastrophic plan or
6. None of the above?
- DK/Ref
$\Rightarrow$ ACS_PATHWAY

\section{ACS_PATHWAY}

There are many different ways to obtain information on the health insurance plans in the marketplace. Which of the following sources of information did you use or try to use to obtain information?

\section{MARK ALL THAT APPLY}

1. Website, including online chat option

2. Newspaper, radio, or television

3. Call center

4. Assistance from navigators, application assisters, certified application counselors, or community health workers

5. Assistance from an insurance agent or broker

6. Assistance from family or friends

7. Assistance from an employer

8. Assistance from a tax preparer

9. Assistance from Medicaid or another program agency such as TANF, SNAP, or WIC

10. Assistance from a hospital, doctor's office, or clinic

11. Other (please specify) $\rightarrow$ ACS_PATHSP (open text specify)

- DK/Ref

$$
\Rightarrow \text { HEALTHSTAT }
$$

\section{HELP SCREENS}

\section{For ACSMCAID:}

Medicaid, medical assistance, or government assistance plans for those with low incomes or a disability may be known by different names in different states. Below is a list of 
program names by state. This list is not comprehensive, but provides guidance for those not familiar with the term Medicaid and may only know their specific state program name. [fill state-specific program name(s) based on the attachment]

\section{For all items except ACSMCAID:}

\section{DATA USES}

- Used to allocate funds to states and local areas for governmentprovided health care.

- Used by federal agencies, such as the Department of Health and Human Services, to evaluate the effectiveness of government health care programs.

- Used by federal and local agencies to examine the adequacy of existing health care facilities in meeting current and future health care needs.

\section{WHY WE ASK IT THIS WAY}

- These questions ask about each type of insurance a respondent may have.

- Insurance can include both private coverage (provided by an employer or purchased) as well as public coverage (from government programs such as Medicare, Medicaid, and VA).

- The reason the question specifies (health insurance or health coverage plans is because many types of public (government) coverage are not technically health insurance plans. The goal of the item is to obtain information on whether an individual has health insurance coverage and if so, what kind of coverage he/she has. 
7.4. Appendix D, Sample Distribution by Strata for Standard and Augmented Samples

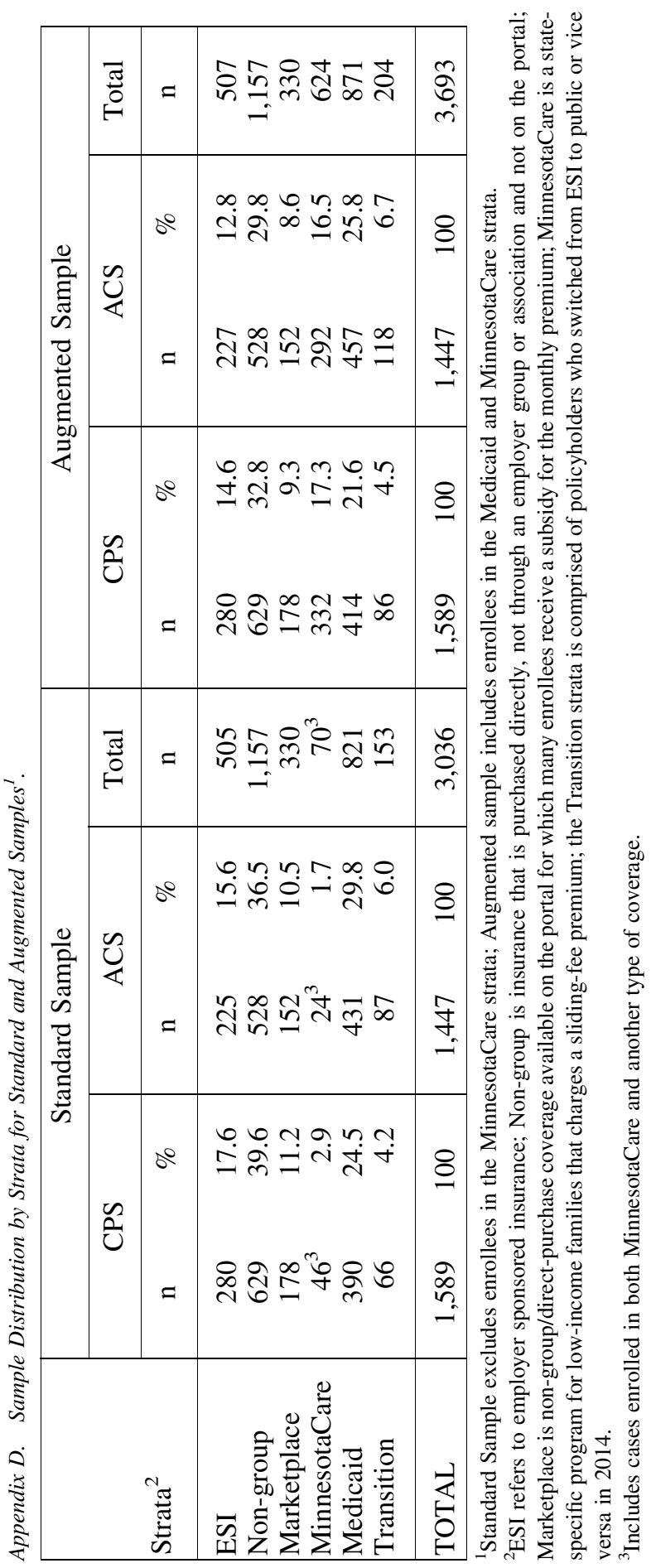




\section{References}

American Association of Public Opinion Research. 2016. Standard Definitions: Final Dispositions of Case Codes and Outcome Rates for Surveys. 9th edition. Available at: https://www.aapor.org/AAPOR_Main/media/publications/Standard-Definitions20169 theditionfinal.pdf (accessed March 2019).

Bennefield, R.L. 1996. Dynamics of Economic Well-Being: Health Insurance, 1992 to 1993, Who Loses Coverage and for How Long? Available at: https://www.census. gov/prod/1/pop/p70-54.pdf (accessed March 2019).

Blewett, L.A. and M. Davern. 2006. "Meeting the Need for State-Level Estimates of Health Insurance Coverage: Use of State and Federal Survey Data." Health Services Research 41(3p1): 946-975. Doi: https://doi.org/10.1111/j.1475-6773.2006.00543.x.

Blumberg, S.J. and M.L. Cynamon. 1999. Misreporting Medicaid Enrollment: Results of three studies linking telephone surveys to state administrative records. Available at: https://www.cdc.gov/nchs/data/hsrmc/hsrmc_7th_proceedings_1999.pdf (accessed March 2019).

Blumberg, S.J., L. Osborn, J.V. Luke, L. Olson, and M.R. Frankel. 2004. "Estimating the prevalence of uninsured children: an evaluation of data from the National Survey of Children with Special Health Care Needs, 2001." Vital and Health Statistics. Series 2, (136): i-38. Available at: https://www.cdc.gov/nchs/data/series/sr_02/sr02_136.pdf (accessed March 2019).

Call, K.T., M.E. Davern, J.A. Klerman, and V. Lynch. 2013. "Comparing errors in Medicaid reporting across surveys: Evidence to date." Health Services Research 48(2 PART1): 652-664. Doi: https://doi.org/10.1111/j.1475-6773.2012.01446.x.

Call, K.T., A.R. Fertig, J. Pascale, and D. Oellerich. 2018. Who gets it right? Characteristics associated with accurate reporting of health insurance coverage. In Paper presented at the Academy Health Annual Research Meeting, Seattle, WA. U.S.A. June 25, 2018. Available at: https://www.academyhealth.org/events/2018-06/2018annual-research-meeting (accessed March 2019).

Cantor, J.C., A.C. Monheit, S. Brownlee, and C. Schneider. 2007. "The adequacy of household survey data for evaluating the nongroup health insurance market." Health Services Research 42(4): 1739-1757. Doi: https://doi.org/10.1111/j.1475-6773.2006. 00662.x.

Czajka, J.L. and K. Lewis. 1999. Using National Survey Data to Analyze Children's Health Insurance Coverage: An Assessment of Issues. Available at: https:/www.mathematica-mpr.com/our-publications-and-findings/publications/using-national-surveydata-to-analyze-childrens-health-insurance-coverage-an-assessment-of-issues (accessed March 2019).

Davern, M., K.T. Call, J. Ziegenfuss, G. Davidson, T.J. Beebe, and L. Blewett. 2008. "Validating health insurance coverage survey estimates: A comparison of self-reported coverage and administrative data records." Public Opinion Quarterly 72(2): 241-259. Doi: https://doi.org/10.1093/poq/nfn013.

Eberly, T., M.B. Pohl, and S. Davis. 2009. "Undercounting Medicaid enrollment in Maryland: Testing the accuracy of the current population survey." Population Research and Policy Review 28(2): 221-236. Doi: https://doi.org/10.1007/s11113-008-9078-5. 
Farley-Short, P. 2001. Counting and Characterizing the Uninsured. Available at: http:// rwjf-eriu.org/pdf/farleyshort-final.pdf (accessed March 2019).

Fertig, A.R., J. Pascale, K.T. Call, and D. Oellerich. 2018. Design and Sampling Strategy for a Validation Study Linking Enrollment Records to Survey Reports: the CHIME Study. Available at: https://www.census.gov/content/dam/Census/library/workingpapers/2018/adrm/rsm2018-10.pdf (accessed December 2018).

Hill, S.C. 2007. "The Accuracy of Reported Insurance Status in the MEPS.” Inquiry 44(4): 443-468. Doi: https://doi.org/10.5034/inquiryjrnl_44.4.443.

Klerman, J.A., M. Davern, K.T. Call, V. Lynch, and J.D. Ringel. 2009. "Understanding The Current Population Survey's Insurance Estimates And The Medicaid 'Undercount'." Health Affairs 28(6): w991-w1001. Doi: https://doi.org/10.1377/ hlthaff.28.6.w991.

Lewis, K., M.R. Ellwood, and J.L. Czajka. 1998. Counting the Uninsured: A Review of the Literature. Available at: https://www.urban.org/research/publication/countinguninsured (accessed March 2019).

Lurie, I.Z. and J. Pearce. 2018. Health Insurance Coverage from Administrative Tax Data. Available at: https://www.treasury.gov/resource-center/tax-policy/Pages/tax_analysis_paper.aspx (accessed May 2019).

Mach, A. and B. O'Hara. 2011. Do people really have multiple health insurance plans? Estimates of Nongroup Health Insurance in the American Community Survey. Available at: https://www.census.gov/content/dam/Census/library/workingpapers/2011/demo/SEHSD-WP2011-28.pdf (accessed March 2019).

Marquis, M.S. 1983. "Consumers' Knowledge about their Health Insurance Coverage." Health Care Financ Rev 5(1): 65-80. Available at: http://www.ncbi.nlm.nih.gov/pmc/ articles/PMC4191335/ (accessed May 2019).

Minnesota Department of Health. 2018. Section 4: Individual and Small Group Health Insurance Markets - Chart Summaries. Available at: https://www.health.state.mn.us/ data/economics/chartbook/summaries/section4summaries.html (accessed March 2019).

Nelson, D.E., B.L. Thompson, N.J. Davenport, and L.J. Penaloza. 2000. "What people really know about their health insurance: A comparison of information obtained from individuals and their insurers." American Journal of Public Health 90(6): 924-928. Doi: https://doi.org/10.2105/AJPH.90.6.924.

Noon, J.M., L.E. Fernandez, and S.R. Porter. 2019. "Response error and the Medicaid undercount in the current population survey." Health Services Research, 54(1): 34-43. Doi: https://doi.org/10.1111/1475-6773.13058.

Pascale, J. 2008. "Measurement Error in Health Insurance Reporting." Inquiry 45(4): 422-437. Doi: https://doi.org/10.5034/inquiryjrnl_45.04.422.

Pascale, J. 2009. Health Insurance Measurement A Synthesis of Cognitive Testing Findings. In Questionnaire Evaluation Standards (QUEST) Meeting, May 18-20. Bergen, Norway. Available at: https://wwwn.cdc.gov/qbank/QUest/2009/pres10.pdf (accessed March 2019).

Pascale, J. 2016. "Modernizing a major federal government survey: A Review of the redesign of the current population survey health insurance questions." Journal of Official Statistics 32(2): 461-486. Doi: https://doi.org/10.1515/JOS-2016-0024. 
Pascale, J., M. Boudreaux, and R. King. 2016. "Understanding the New Current Population Survey Health Insurance Questions." Health Services Research 51(1): 240-261. Doi: https://doi.org/10.1111/1475-6773.12312.

Pascale, J., K.T. Call, and A.R. Fertig. 2018a. Using a Machine Learning Approach to Classify Health Insurance Type from Survey Responses Using Enrollment Data. In Paper presented at the AcademyHealth Annual Research Meeting, Seattle, WA.U.S.A. June 25, 2018. Available at: https://www.academyhealth.org/events/2018-06/2018annual-research-meeting (accessed March 2019).

Pascale, J., K.T. Call, and A.R. Fertig. 2018b. Using Enrollment Records to Guide Categorization of Health Insurance Coverage Type Post-ACA. In Paper presented at the AcademyHealth Annual Research Meeting, Seattle, WA.U.S.A. June 25, 2018. Available at: https://www.academyhealth.org/events/2018-06/2018-annual-researchmeeting (accessed May 2019).

Pascale, J., J. Rodean, L. Leeman, C. Cosenza, and A. Schoua-Glusberg. 2013. "Preparing to Measure Health Coverage in Federal Surveys Post-Reform." Inquiry 50(2): 106-123. Doi: https://doi.org/10.1177/0046958013513679.

Pascale, J., M.I. Roemer, and D.M. Resnick. 2009. Medicaid underreporting in the CPS: Results from a Record Check Study. Public Opinion Quarterly 73(3): 497-520. Doi. https://doi.org/10.1093/poq/nfp028.

Rosenbach, M. and K. Lewis. 1998. Estimates of Health Insurance Coverage in the Community Tracking Study and the Current Population Survey. Available at: https://www.researchgate.net/publication/267196753_Estimates_of_Health_Insurance_Coverage_in_the_Community_Tracking_Study_and_the_Current_Population_Survey (accessed March 2019).

Swartz, K. 1986. "Interpreting the Estimates from Four National Surveys of the Number of People Without Health Insurance." Journal of Economic and Social Measurement 14(3): 233-242. Doi: https://doi.org/10.3233/JEM-1986-14306.

U.S. Census Bureau. 2016a. Table DP05 ACS Demographic and Housing Estimates. Available at: http://factfinder.census.gov/faces/tableservices/jsf/pages/productview. xhtml? src = CF (accessed June 2016).

U.S. Census Bureau. 2016b. Table S1201 Educational Attainment. Available at: http:// factfinder.census.gov/faces/tableservices/jsf/pages/productview.xhtml src $=\mathrm{CF}$ (accessed June 2016).

Received April 2018

Revised February 2019

Accepted March 2019 